REVISTA DE LA CEPAL 82 . ABRIL 2004

\title{
Hogares, pobreza y políticas en épocas de crisis.
}

\section{México, 1992-1996}

\author{
Benjamin Davis, Sudhanshu Handa y Humberto Soto
}

Benjamín Davis

Economista,

Organización de las Naciones Unidas para la Agricultura y la Alimentación/ESA

• benjamin.davis@fao.org

Sudhanshu Handa

Profesor Adjunto,

Departamento de Políticas Públicas, Universidad de Carolina del Norte

• shanda@mail.unc.edu

Humberto Soto

Investigador Adjunto,

Departamento de Economía,

Universidad Iberoamericana,

México, D.F.

๑ humberto.soto@uia.mx

n la década anterior a la crisis de 1995, mejoraron en México los indicadores de desarrollo humano. Aplicando técnicas de descomposición, el artículo mide el efecto de esas mejoras en las condiciones de los hogares para enfrentar la crisis. La caída del consumo entre 1994 y 1996 se explica con creces por la reducción de la rentabilidad de las diversas características de los hogares, en tanto que la variación de éstas sirvió para mitigar (si bien en mucho menor medida) los efectos negativos de la crisis. De haberse mantenido las características de 1992 de los hogares, la pobreza rural en 1996 habría superado en 48\% la magnitud observada. Por otro lado, la simulación muestra que si en ese período hubiese existido el programa PROGRESA, al cabo de un año la brecha de pobreza rural y su severidad habrían disminuido. Se concluye que los programas sociales orientados al desarrollo de largo plazo también pueden servir como medidas de protección durante una crisis macroeconómica. 


\section{I}

\section{Introducción}

En 1995, México atravesó por una de las peores crisis económicas de su historia reciente, en el curso de la cual el PIB per cápita cayó $9 \%$ y los salarios reales se redujeron $25 \%$. Sin embargo, la crisis fue precedida por más de un decenio de mejoramiento de los indicadores sociales y económicos y por cambios estructurales importantes en la economía. Sin duda alguna, cuando se desencadenó la crisis la sociedad mexicana no era la misma de diez años antes. Cabe entonces preguntarse hasta qué punto estos cambios de largo plazo de la sociedad mexicana influyeron en la capacidad de los hogares de soportar la crisis y, en definitiva, de superarla. Para responder a ese interrogante, volvemos al problema central de "crecimiento versus desarrollo", que ha preocupado a los estudiosos del desarrollo desde comienzos del decenio de 1980. En los cinco años anteriores a la crisis del peso, el PIB mexicano creció en promedio un 3\% anual pero, lo que es más importante, el país había estado inserto en un período aún más prolongado de desarrollo, como lo demuestran la caída de la mortalidad infantil (niños de 0 a 1 año) y el mayor acceso a la educación, así como las reformas estructurales llevadas a cabo. Lo que nos propusimos fue cuantificar en qué medida este "desarrollo" sirvió para mitigar las consecuencias negativas de la crisis macroeconómica de 1995. Al perseguir esta finalidad, contribuimos al conocimiento de las ventajas e inconvenientes que acarrea la aplicación de estrategias de desarrollo que centran la atención en un concepto restringido del crecimiento económico, comparadas con aquéllas que persiguen simultáneamente objetivos de crecimiento y desarrollo.
En este artículo comenzamos por describir la crisis mexicana y pasar revista al desempeño del país en materia de pobreza, crecimiento e indicadores sociales. A continuación, examinamos la forma en que reaccionaron los hogares a la crisis macroeconómica de 1995. Luego, utilizando técnicas estándares, descompusimos las variaciones del consumo que se produjeron en 1992, 1994 y 1996, distinguiendo entre las que obedecieron a diferencias en el entorno y en las instituciones y aquéllas que se debieron a diferencias en las características de los hogares. Por último, investigamos el papel que pueden desempeñar los programas sociales en la mitigación y alivio de la pobreza durante las crisis macroceconómicas, examinando dos de los principales programas sociales mexicanos: el Programa de Apoyos Directos al Campo (Procampo) y el Programa de Educación, Salud y Alimentación (PROGRESA), ahora llamado Oportunidades.

Nuestro análisis se basa en los datos de tres encuestas nacionales sucesivas - de 1992, 1994 y 1996sobre los ingresos y gastos de los hogares (ENIGH), llevadas a cabo por el Instituto Nacional de Estadística, Geografía e Informática (INEGI) de México. Las encuestas mencionadas no ofrecen observaciones de datos de panel, sino más bien observaciones repetidas de corte transversal que abarcan todas las formas de ingresos y gastos. La encuesta correspondiente a 1994 se llevó a cabo antes de la crisis, de modo que los efectos de este shock exógeno se captaron comparando las encuestas de 1994 y 1996.

Agradecemos las observaciones de Marco Stampini, Gabriel Demombynes, Daniel Hernández, Oscar Altimir y un comentarista anónimo. Asimismo, agradecemos a Emmanuel Skoufias sus primeros trabajos para construir los agregados del consumo y a Susan Parker por la información que nos proporcionó. Además, querríamos mencionar a José Gómez de León (1946-2000), quien formuló observaciones a una versión anterior de este trabajo y con quien tuvimos el honor de trabajar en el programa PROGRESA. 


\section{II}

\section{Reforma económica y crisis}

Durante la presidencia de Carlos Salinas de Gortari (1988-1994), México inició un programa de reformas económicas estructurales. Tales reformas constituyeron una reacción a la serie de crisis que había afectado a la economía mexicana desde 1976, así como a la estrategia de desarrollo basada en la sustitución de importaciones que se había aplicado en el país a lo largo de los decenios anteriores. El gobierno suscribió el Acuerdo General sobre Aranceles Aduaneros y Comercio (GATT), firmó el Tratado de Libre Comercio (TLC) de América del Norte con Canadá y los Estados Unidos; privatizó la mayoría de las empresas estatales; inició cambios en el sistema de tenencia de la tierra en el sector ejidal (de reforma agraria) mediante la modificación del artículo 27 de la Constitución, lo que afectó a más de la mitad del territorio mexicano; y modificó el papel que desempeñaba el Estado en el crédito, la comercialización y otros servicios de apoyo a la agricultura.

En el primer año de gobierno del presidente Ernesto Zedillo (1994-2000), la sobrevaluación del tipo de cambio y la dependencia de inversiones extranjeras de corto plazo de carácter inestable condujeron a una grave crisis cambiaria. Esta desembocó en una fuerte devaluación (120\% entre diciembre de 1994 y marzo de 1995), elevadas tasas de inflación, alzas desorbitadas de las tasas de interés real, e inestabilidad macroeconómica hasta 1996. En 1995, el PIB real cayó más de $6 \%(8,6 \%$ per cápita) al entrar la economía en un severo ciclo recesivo. $\mathrm{Al}$ año siguiente la economía repuntó, creciendo $5 \%$ (casi $3 \%$ per cápita). Pese a la reactivación, sin embargo, entre 1994 y 1996 el salario medio real por día tuvo una caída de $24 \%$ (tras aumentar $21 \%$ entre 1992 y 1994) y en 1997 se mantuvo prácticamente invariable (Banco de México, 1999; INEGI, 1999).

La crisis golpeó con más fuerza los ingresos salariales que los no salariales, lo que influyó para que las zonas urbanas se vieran más severamente afectadas por la consiguiente baja del consumo. Mientras que en las zonas rurales el consumo per cápita se redujo un $4 \%$, en las zonas urbanas tuvo una sorprendente caída de $27 \%$ entre 1994 y 1996 . Como puede verse en los cuadros 1 y 2 , en las zonas urbanas el consiguiente incremento de las tasas de pobreza extrema y moderada triplicó con creces las de las zonas rurales. Más adelante se examinan estos cambios con mayor detalle.

CUADRO 1

México: Incidencia de la pobreza, según el umbral de pobreza relativa, 1992, 1994 y 1996

\begin{tabular}{|c|c|c|c|c|c|c|c|c|c|}
\hline & \multicolumn{3}{|c|}{ Nacional } & \multicolumn{3}{|c|}{ Urbana } & \multicolumn{3}{|c|}{ Rural } \\
\hline & 1992 & 1994 & 1996 & 1992 & 1994 & 1996 & 1992 & 1994 & 1996 \\
\hline Consumo mensual per cápita (pesos de 1994) & 650 & 709 & 535 & 772 & 843 & 617 & 265 & 278 & 266 \\
\hline \multicolumn{10}{|l|}{ Porcentaje de hogares en situación de pobreza } \\
\hline Total pobres & 28 & 25 & 31 & 29 & 25 & 36 & 31 & 25 & 28 \\
\hline Pobreza extrema & 12 & 10 & 13 & 12 & 10 & 16 & 15 & 10 & 12 \\
\hline Pobreza moderada & 16 & 15 & 18 & 16 & 15 & 20 & 16 & 15 & 16 \\
\hline
\end{tabular}

Fuente: Elaborado por los autores, con datos de la Encuesta nacional de los ingresos y gastos de los hogares (ENIGH) de 1992,1994 y 1996. 
México: Variación porcentual de la pobreza, según el umbral de pobreza relativa, 1992, 1994 y 1996

\begin{tabular}{|c|c|c|c|c|c|c|}
\hline & \multicolumn{2}{|c|}{ Nacional } & \multicolumn{2}{|c|}{ Urbana } & \multicolumn{2}{|c|}{ Rural } \\
\hline & $1992-94$ & $1994-96$ & 1992-94 & $1994-96$ & 1992-94 & $1994-96$ \\
\hline Consumo mensual per cápita (pesos de 1994) & 9 & -25 & 9 & -27 & 5 & -4 \\
\hline \multicolumn{7}{|l|}{ Porcentaje de hogares en situación de pobreza } \\
\hline Total pobres & -11 & 23 & -13 & 43 & -20 & 13 \\
\hline Pobreza extrema & -18 & 27 & -18 & 61 & -35 & 21 \\
\hline Pobreza moderada & -5 & 21 & -9 & 31 & -5 & 8 \\
\hline
\end{tabular}

Fuente: Elaborado por los autores, con datos de la Encuesta nacional de los ingresos y gastos de los hogares (ENIGH) de 1992,1994 y 1996.

Debido a las restricciones fiscales, el gobierno se vio en apuros para ir en ayuda de las personas afectadas por la crisis. Entre 1994 y 1995, y pese a que se aplicaron medidas de protección social de emergencia, como la puesta en marcha de programas de trabajo transitorio, el gasto social del gobierno disminuyó un $12 \%$ en valores reales (Lustig y Székely, 1998). El gobierno optó, en cambio, por aplicar políticas monetarias y fiscales más severas y continuó realizando ajustes estructurales en la economía.

\section{Las tendencias de largo plazo de los indicadores sociales}

En los últimos decenios, México ha mejorado enormemente la situación económica y las condiciones de vida de su población. Desde 1950, el PIB real per cápita prácticamente se ha duplicado, la proporción de adultos analfabetos ha disminuido de $45 \%$ a $11 \%$ y la de adultos que han completado los seis grados de enseñanza primaria se ha elevado de $10 \%$ a $70 \%$. Entre 1930 y 1995 la mortalidad infantil bajó de 178 por cada mil nacidos vivos a 30,5 por mil y en el mismo período la mortalidad en la niñez (niños de 0 a 5 años) se redujo de 156 a 4,4 por mil. En 1997, más de un $85 \%$ de la población tenía acceso a agua potable (CONAPO, 1997).

La mejora general de los indicadores sociales y demográficos encubre importantes variaciones regionales. Por ejemplo, en promedio, la población masculina de Oaxaca vive 4,7 años menos que la de Nuevo León (CONAPO, 1997). Asimismo, las tasas de mortalidad en la niñez que exhiben Oaxaca, Chiapas y Guerrero duplican con creces las de Ciudad de México, Nuevo León y Baja California. En contradicción con la tendencia nacional, la tasa de mortalidad en la niñez observada en Guerrero se elevó de 36,7 por mil en 1992 a 63,8 por mil en 1997. Al realizar comparaciones entre zonas urbanas y rurales, o según la edad o nivel educativo de la madre, surgen diferencias igualmente importantes (Programa Nacional de Acción a favor de la Infancia, 1998).

Mientras que en 1997 la tasa general de analfabetismo entre los adultos se elevaba a $11 \%$, la cifra oscilaba entre menos de $4 \%$ en Ciudad de México y Nuevo León y más de $20 \%$ en Chiapas, Guerrero y Oaxaca. La proporción de hogares con acceso a agua potable fluctuaba entre $99 \%$ en Sonora y menos de $70 \%$ en Veracruz, Guerrero, Tabasco, Chiapas y Oaxaca. Del mismo modo, mientras que un $99 \%$ de las personas que vivían en Colima disponían de alcantarillado, en Yucatán, Guerrero y Oaxaca la cifra no alcanzaba a $50 \%$ (Programa Nacional de Acción a favor de la Infancia, 1998).

No resulta sorprendente que las tasas de pobreza hayan evolucionado de manera similar. Lustig y Székely (1998) examinaron las estimaciones de las tasas de pobreza correspondientes a los decenios de 1960 y 1970 llevadas a cabo por un grupo de investigadores y comprobaron que, si bien estos en su mayoría disentían en cuanto a los niveles de pobreza, todos coincidían en que en esos años las tasas de pobreza habían disminuido. Hernández Laos (1990) encontró que la pobreza extrema había caído de $70 \%$ en 1963 a 34\% en 1977, mientras que según Székely (1998) ésta se había reducido de $30 \%$ a $18 \%$ en el mismo período.

Según Lustig y Székely (1998), entre 1984 y 1989 aumentaron tanto la pobreza extrema y moderada como la desigualdad. Entre 1989 y 1994 los indicadores nacionales de pobreza y desigualdad no registraron grandes variaciones. Sin embargo, estas cifras nacionales una vez más ocultan la variación regional, puesto que en el sur la incidencia de la pobreza tuvo un importante incremento. Como lo revela el trabajo de estos autores y lo indican nuestros propios datos, que se ofrecen más adelante, en México la pobreza está fuertemente concentrada en el sur del país. 


\section{III}

\section{Los cambios en las características de los pobres, 1992 a 1996}

Nuestra hipótesis es que la crisis del período 1994-1995 condujo a una modificación de las características de los hogares que vivían en situación de pobreza, como lo establece una medida del bienestar basada en el consumo. Dado el fuerte impacto de la crisis en las tasas de interés y los salarios reales, cabía esperar que los niveles de consumo de los hogares de ingresos medios y bajos tendrían una caída más pronunciada. En consecuencia, el número de pobres aumentaría al agregarse a ellos familias de nivel educativo relativamente más alto, con una estructura demográfica más madura y que exhiben otros indicadores de mayor bienestar a largo plazo. Comprobamos que si bien en promedio las características de los pobres evolucionan en la forma prevista, marginalmente esas mismas características, como el nivel educativo, influyen aún más en la reducción de sus probabilidades de caer en la pobreza.

\section{El aumento de la pobreza}

Si se utiliza el consumo como medida básica del bienestar, casi invariablemente se llega a la conclusión de que la proporción de hogares mexicanos que vivía en situación de pobreza aumentó entre 1994 y 1996, dada la baja del consumo per cápita observada en ese período. Sin embargo, como hay grandes discrepancias entre el gobierno y los organismos internacionales sobre cuál es el umbral de pobreza adecuado, las estimaciones del número de pobres del país varían mucho. ${ }^{2}$ Como la idea es examinar los cambios en el consumo y la pobreza entre 1992 y 1996, sin entrar a discutir el número exacto de pobres que había entonces en México, optamos por utilizar un umbral de pobreza relativa. En consecuencia, seleccionamos como línea de la pobreza extrema el nivel de consumo correspondiente al décimo percentil en 1994 y como línea de la pobreza moderada el nivel de consumo del vigésimo quinto percentil ese mismo año.

\footnotetext{
2 Aunque las estimaciones de la incidencia de la pobreza varían, en general tienden a evolucionar de manera similar: las tasas de pobreza disminuyen hasta 1994, en 1996 tienden a aumentar debido a la crisis, para luego bajar gradualmente. Véase, por ejemplo, CEPAL (2002).
}

Valiéndose de precios constantes de 1994 es posible comparar las variaciones del índice de incidencia de la pobreza (cuadros 1 y 2). De acuerdo con nuestra definición, el año 1994, año anterior a la crisis, parece haber sido positivo en lo que respecta a la reducción de la pobreza. Entre 1992 y 1994, el consumo mensual medio per cápita aumentó tanto en las zonas urbanas como en las rurales, mientras que la proporción de hogares que se situaron por debajo del umbral de pobreza se redujo. Sin embargo, como ya se dijo, entre 1994 y 1996 estas mejoras se anularon con creces, particularmente en las zonas urbanas. La proporción de hogares urbanos en situación de pobreza extrema aumentó más de $60 \%$, mientras que la de aquellos en condiciones de pobreza moderada se elevó 30\%.

\section{Semblanza de la pobreza}

El cuadro 3 muestra los valores medios de diversas características de los hogares, por año, ubicación y situación en materia de pobreza. En este caso, encontramos pruebas que confirman nuestra hipótesis de que la crisis afectó a familias que tenían una situación relativamente más acomodada, lo que se tradujo en una modificación de las características generales de los hogares pobres. Hubo mejoras en las características de los hogares en situación de pobreza extrema y moderada, especialmente de 1994 a 1996. Los pobres de las zonas urbanas exhibían un nivel educativo más alto; poseían más bienes de consumo duraderos, como equipos de música, refrigeradores y equipos de video; tenían menos hijos pequeños, y la proporción de las familias que habitaban viviendas con piso de tierra era menor. En 1996, los pobres de las zonas rurales poseían más bienes de consumo duraderos, un número menor de ellos habitaba en viviendas con piso de tierra y los miembros de la familia tenían un nivel educativo más alto. 
México: Características de los hogares pobres, en zonas urbanas y rurales, 1992, 1994 y 1996

\begin{tabular}{|c|c|c|c|c|c|c|c|c|c|}
\hline & \multicolumn{3}{|c|}{ Pobreza extrema } & \multicolumn{3}{|c|}{ Moderadamente pobres } & \multicolumn{3}{|c|}{ No pobres } \\
\hline & 1992 & 1994 & 1996 & 1992 & 1994 & 1996 & 1992 & 1994 & 1996 \\
\hline \multicolumn{10}{|l|}{ Zonas urbanas } \\
\hline Número de miembros sin enseñanza primaria & 1,14 & 1,21 & 0,95 & 0,71 & 0,86 & 0,57 & 0,32 & 0,32 & 0,24 \\
\hline Número de miembros con enseñanza primaria & 0,81 & 0,71 & 0,83 & 0,75 & 0,84 & 0,61 & 0,46 & 0,43 & 0,35 \\
\hline Número de miembros con ens. secundaria o técnica & 0,55 & 0,45 & 0,68 & 0,73 & 0,75 & 0,90 & 0,85 & 0,90 & 0,88 \\
\hline Número de miembros con estudios superiores & 0,03 & 0,02 & 0,03 & 0,05 & 0,04 & 0,09 & 0,24 & 0,25 & 0,30 \\
\hline Número de miembros de 0 a 4 años & 0,95 & 1,05 & 0,94 & 0,65 & 0,80 & 0,58 & 0,39 & 0,39 & 0,35 \\
\hline Proporción de hogares que tiene equipos de música & 0,23 & 0,14 & 0,20 & 0,27 & 0,21 & 0,33 & 0,57 & 0,52 & 0,51 \\
\hline Proporción de hogares que tiene aparatos de video & 0,09 & 0,10 & 0,11 & 0,20 & 0,22 & 0,25 & 0,50 & 0,51 & 0,50 \\
\hline Proporción de hogares que tiene refrigerador & 0,28 & 0,32 & 0,42 & 0,56 & 0,57 & 0,68 & 0,85 & 0,85 & 0,87 \\
\hline Proporción de hogares que tiene piso de tierra & 0,28 & 0,26 & 0,21 & 0,13 & 0,13 & 0,07 & 0,03 & 0,03 & 0,02 \\
\hline Número de observaciones & 704 & 722 & 1404 & 950 & 1081 & 1721 & 4116 & 5405 & 5610 \\
\hline \multicolumn{10}{|l|}{ Zonas rurales } \\
\hline Número de miembros sin enseñanza primaria & 1,65 & 1,62 & 1,70 & 1,45 & 1,44 & 1,36 & 0,98 & 0,96 & 0,80 \\
\hline Número de miembros con enseñanza primaria & 0,39 & 0,59 & 0,67 & 0,56 & 0,60 & 0,72 & 0,59 & 0,57 & 0,57 \\
\hline Número de miembros con ens. secundaria o técnica & 0,08 & 0,13 & 0,16 & 0,20 & 0,17 & 0,27 & 0,38 & 0,37 & 0,47 \\
\hline Número de miembros con estudios superiores & 0,00 & 0,00 & 0,00 & 0,00 & 0,00 & 0,00 & 0,01 & 0,02 & 0,03 \\
\hline Número de miembros de 0 a 4 años & 1,38 & 1,36 & 1,47 & 0,98 & 0,95 & 0,99 & 0,59 & 0,56 & 0,53 \\
\hline Proporción de hogares que tiene equipos de música & 0,01 & 0,02 & 0,04 & 0,06 & 0,05 & 0,12 & 0,15 & 0,15 & 0,17 \\
\hline Proporción de hogares que tiene aparatos de video & 0,00 & 0,02 & 0,01 & 0,02 & 0,02 & 0,04 & 0,10 & 0,11 & 0,13 \\
\hline Proporción de hogares que tiene refrigerador & 0,02 & 0,04 & 0,05 & 0,11 & 0,10 & 0,17 & 0,34 & 0,36 & 0,42 \\
\hline Proporción de hogares que tiene piso de tierra & 0,76 & 0,75 & 0,69 & 0,66 & 0,53 & 0,48 & 0,34 & 0,28 & 0,25 \\
\hline Número de observaciones & 605 & 482 & 539 & 620 & 721 & 723 & 2712 & 3604 & 3191 \\
\hline
\end{tabular}

Fuente: Elaborado por los autores, con datos de la Encuesta nacional de los ingresos y gastos de los hogares (ENIGH) de 1992,1994 y 1996.

Para determinar las probabilidades de que un hogar fuera pobre se estimaron ecuaciones Probit (combinando la pobreza extrema y la moderada) para los tres años, por zonas urbanas y rurales. Los resultados figuran en los cuadros 4 y 5 . Comprobamos que si bien los efectos medios reflejan las cambiantes características generales de los pobres, marginalmente, en 1996 un nivel educativo más alto, por ejemplo, contribuyó de manera aún más marcada a reducir las probabilidades de vivir en condición de pobreza. Del mismo modo, mientras que los hogares pobres, en especial los de zonas urbanas, generalmente tienen cada vez menos hijos, el hecho de tener más hijos pequeños y adolescentes aumentó significativamente las probabilidades de que la familia viviera en situación de pobreza en 1996.

El papel desempeñado por las actividades laborales se mantuvo relativamente constante: tanto en las zonas urbanas como en las rurales el trabajo asalariado no agrícola conllevaba menores probabilidades de vivir en situación de pobreza, mientras que lo contrario ocurría con el trabajo asalariado agrícola. Por su parte, las actividades de empleo por cuenta propia variaban de signo según el año: tratándose de hogares urbanos, en 1992 y 1996 el empleo por cuenta propia se acompañó de una elevada probabilidad de ser pobre, mientras que en 1994 sucedió lo contrario. En general, los resultados correspondientes a 1996 revelan que las probabilidades de caer en la pobreza eran mucho mayores para las familias más jóvenes, que tenían más hijos pequeños y adolescentes, cuyos jefes de hogar y familiares no jefes de hogar tenían menor nivel educativo, y que vivían en la región del Pacífico sur (así como para los hogares urbanos de la región del Golfo). 
México: Estimación Probit de las probabilidades de vivir en situación de pobreza (extrema y moderada combinadas), hogares urbanos, 1992, 1994 y $1996^{a}$

\begin{tabular}{|c|c|c|c|c|c|c|}
\hline & \multicolumn{2}{|c|}{1992} & \multicolumn{2}{|c|}{1994} & \multicolumn{2}{|c|}{1996} \\
\hline & Coef & $\mathrm{P}>|\mathrm{z}|$ & Coef & $\mathrm{P}>|\mathrm{z}|$ & Coef & $\mathrm{P}>|\mathrm{z}|$ \\
\hline Edad del jefe de hogar & $-0,001$ & 0,40 & $-0,001$ & 0,43 & $-0,002$ & $0,02 * *$ \\
\hline Mujer jefe de hogar & 0,001 & 0,98 & $-0,026$ & 0,11 & $-0,011$ & 0,61 \\
\hline Ln (tamaño del hogar) & 0,296 & $0,00 * * *$ & 0,137 & $0,00 * * *$ & 0,181 & $0,00 * * *$ \\
\hline Jefe de hogar con enseñanza primaria incompleta & $-0,089$ & $0,00 * * *$ & $-0,078$ & $0,00 * * *$ & $-0,119$ & $0,00 * * *$ \\
\hline Jefe de hogar con enseñanza primaria completa & $-0,139$ & $0,00 * * *$ & $-0,124$ & $0,00 * * *$ & $-0,227$ & $0,00 * * *$ \\
\hline Jefe de hogar con enseñanza secundaria incompleta & $-0,182$ & $0,00 * * *$ & $-0,171$ & $0,00 * * *$ & $-0,288$ & $0,00 * * *$ \\
\hline Jefe de hogar con enseñanza vocacional o técnica incompleta & $-0,209$ & $0,00 * * *$ & $-0,183$ & $0,00 * * *$ & $-0,334$ & $0,00 * * *$ \\
\hline Jefe de hogar con estudios superiores incompletos & $-0,265$ & $0,00 * * *$ & $-0,234$ & $0,00 * * *$ & $-0,407$ & $0,00 * * *$ \\
\hline $\mathrm{N}^{\circ}$ de miembros sin estudios & $-0,011$ & 0,48 & 0,056 & $0,00 * * *$ & 0,080 & $0,00 * * *$ \\
\hline $\mathrm{N}^{\circ}$ de miembros con enseñanza primaria completa & $-0,041$ & $0,01 * * *$ & 0,008 & 0,51 & 0,022 & 0,18 \\
\hline $\mathrm{N}^{\circ}$ de miembros con enseñanza secundaria o técnica & $-0,088$ & $0,00 * * *$ & $-0,053$ & $0,00 * * *$ & $-0,062$ & $0,00 * * *$ \\
\hline $\mathrm{N}^{\circ}$ de miembros con algunos estudios superiores & $-0,152$ & $0,00 * * *$ & $-0,114$ & $0,00 * * *$ & $-0,172$ & $0,00 * * *$ \\
\hline Tasa de dependencia de los hogares ${ }^{b}$ & 0,353 & $0,00 * * *$ & 0,064 & 0,13 & 0,215 & $0,00 * * *$ \\
\hline $\mathrm{N}^{\circ}$ de miembros de 0 a 4 años & 0,043 & $0,00 * * *$ & 0,075 & $0,00 * * *$ & 0,121 & $0,00 * * *$ \\
\hline $\mathrm{N}^{\circ}$ de miembros de 5 a 10 años & 0,010 & 0,38 & 0,058 & $0,00 * * *$ & 0,087 & $0,00 * * *$ \\
\hline $\mathrm{N}^{\circ}$ de miembros varones de 11 a 14 años & 0,011 & 0,47 & 0,044 & $0,00 * * *$ & 0,089 & $0,00 * * *$ \\
\hline $\mathrm{N}^{\circ}$ de miembros mujeres de 11 a 14 años & $-0,008$ & 0,58 & 0,027 & $0,03 * *$ & 0,105 & $0,00 * * *$ \\
\hline $\mathrm{N}^{\circ}$ de miembros varones de 15 a 19 años & 0,067 & $0,00 * * *$ & 0,030 & $0,02 * *$ & 0,096 & $0,00 * * *$ \\
\hline $\mathrm{N}^{\circ}$ de miembros mujeres de 15 a 19 años & 0,060 & $0,00 * * *$ & 0,053 & $0,00 * * *$ & 0,075 & $0,00 * * *$ \\
\hline $\mathrm{N}^{\circ}$ de miembros varones de 20 a 34 años & 0,047 & $0,00 * * *$ & 0,020 & $0,05 * *$ & 0,058 & $0,00 * * *$ \\
\hline $\mathrm{N}^{\circ}$ de miembros mujeres de 20 a 34 años & 0,037 & $0,00 * * *$ & 0,003 & 0,75 & 0,031 & $0,02 * *$ \\
\hline $\mathrm{N}^{\circ}$ de miembros varones de 55 años o más & 0,029 & 0,18 & $-0,007$ & 0,66 & 0,014 & 0,53 \\
\hline $\mathrm{N}^{\circ}$ de miembros mujeres de 55 años o más & 0,039 & $0,04 * *$ & $-0,016$ & 0,26 & 0,029 & 0,11 \\
\hline $\mathrm{N}^{\circ}$ de asalariados no agrícolas & $-0,007$ & 0,54 & $-0,027$ & $0,01 * * *$ & $-0,032$ & $0,02 * *$ \\
\hline $\mathrm{N}^{\mathrm{o}}$ de asalariados agrícolas & 0,064 & $0,01 * * *$ & 0,080 & $0,00 * * *$ & 0,062 & $0,03 * *$ \\
\hline $\mathrm{N}^{\circ}$ que trabaja por cuenta propia & 0,051 & $0,00 * * *$ & $-0,031$ & $0,01 * * *$ & 0,029 & $0,07 *$ \\
\hline $\mathrm{N}^{\circ}$ que trabaja su propia tierra & 0,019 & 0,33 & $-0,010$ & 0,45 & $-0,058$ & $0,00 * * *$ \\
\hline Vivienda propia & $-0,076$ & $0,00 * * *$ & $-0,053$ & $0,00 * * *$ & $-0,054$ & $0,01 * * *$ \\
\hline Arrendatarios & $-0,134$ & $0,00 * * *$ & $-0,082$ & $0,00 * * *$ & $-0,140$ & $0,00 * * *$ \\
\hline Jefe de hogar trabaja en sector agrícola & 0,129 & $0,00 * * *$ & 0,063 & $0,02 * *$ & 0,138 & $0,00 * * *$ \\
\hline Jefe de hogar trabaja en sector manufacturero & 0,051 & $0,05 * *$ & $-0,026$ & 0,18 & 0,105 & $0,00 * * *$ \\
\hline Jefe de hogar trabaja en transp. / serv. de utilidad pública / comercio & 0,033 & 0,14 & $-0,010$ & 0,56 & 0,093 & $0,00 * * *$ \\
\hline Jefe de hogar trabaja en sector público o de defensa & 0,032 & 0,28 & $-0,038$ & $0,08 *$ & 0,032 & 0,27 \\
\hline Jefe de hogar trabaja en sector servicios & 0,028 & 0,27 & $-0,022$ & 0,23 & 0,109 & $0,00 * * *$ \\
\hline Norte & $-0,111$ & $0,00 * * *$ & $-0,051$ & $0,02 * *$ & $-0,064$ & $0,01 * * *$ \\
\hline Pacífico norte & $-0,155$ & $0,00 * * *$ & $-0,110$ & $0,00 * * *$ & $-0,162$ & $0,00 * * *$ \\
\hline Centro & $-0,059$ & $0,01 * * *$ & $-0,043$ & $0,04 * *$ & $-0,049$ & $0,03 * *$ \\
\hline Golfo & $-0,101$ & $0,00 * * *$ & $-0,014$ & 0,53 & 0,017 & 0,52 \\
\hline Zona urbana metropolitana & $-0,191$ & $0,00 * * *$ & $-0,142$ & $0,00 * * *$ & $-0,148$ & $0,00 * * *$ \\
\hline Número de observaciones & & 5723 & & 7145 & & 8678 \\
\hline
\end{tabular}

Fuente: Elaborado por los autores, con datos de la Encuesta nacional de los ingresos y gastos de los hogares (ENIGH) de 1992,1994 y 1996.

a Los coeficientes son probabilidades marginales derivadas de los coeficientes Probit. La categoría excluida respecto del jefe de hogar corresponde a sin educación.

*** Significativo al $1 \%$

** Significativo al $5 \%$.

* Significativo al 10\%.

b La tasa de dependencia de los hogares corresponde a la razón entre el número de ocupados del hogar y el número total de personas que componen el hogar. 
CUADRO 5

México: Estimación Probit de las probabilidades de vivir en situación de pobreza (extrema y moderada combinadas), hogares rurales ${ }^{a}$

\begin{tabular}{|c|c|c|c|c|c|c|}
\hline & \multicolumn{2}{|c|}{1992} & \multicolumn{2}{|c|}{1994} & \multicolumn{2}{|c|}{1996} \\
\hline & Coef & $\mathrm{P}>|\mathrm{z}|$ & Coef & $\mathrm{P}>|\mathrm{z}|$ & Coef & $\mathrm{P}>|\mathrm{z}|$ \\
\hline Edad del jefe de hogar & 0,000 & 0,90 & $-0,001$ & 0,19 & $-0,002$ & $0,03 * *$ \\
\hline Mujeres jefes de hogar & 0,018 & 0,59 & 0,034 & 0,17 & 0,005 & 0,85 \\
\hline Ln (tamaño de la familia) & 0,201 & $0,00 * * *$ & 0,207 & $0,00 * * *$ & 0,111 & $0,02 * *$ \\
\hline Jefe de hogar con enseñanza primaria incompleta & $-0,094$ & $0,00 * * *$ & $-0,042$ & $0,00 * * *$ & $-0,031$ & 0,06 \\
\hline Jefe de hogar con enseñanza primaria completa & $-0,131$ & $0,00 * * *$ & $-0,084$ & $0,00 * * *$ & $-0,099$ & $0,00 * * *$ \\
\hline Jefe de hogar con estudios secundarios o superiores incompletos & $-0,178$ & $0,00 * * *$ & $-0,121$ & $0,00 * * *$ & $-0,146$ & $0,00 * * *$ \\
\hline $\mathrm{N}^{\circ}$ de miembros familia sin estudios & 0,001 & 0,94 & 0,014 & 0,25 & 0,037 & $0,02 * *$ \\
\hline $\mathrm{N}^{\circ}$ de miembros con enseñanza primaria completa & $-0,068$ & $0,00 * * *$ & $-0,023$ & $0,07 *$ & $-0,027$ & $0,10 *$ \\
\hline $\mathrm{N}^{\circ}$ de miembros con enseñanza secundaria o técnica & $-0,081$ & $0,00 * * *$ & $-0,068$ & $0,00 * * *$ & $-0,080$ & $0,00 * * *$ \\
\hline $\mathrm{N}^{\circ}$ de miembros con algunos estudios superiores & $-0,189$ & $0,03 * *$ & $-0,170$ & $0,02 * *$ & $-0,339$ & $0,01 * * *$ \\
\hline Tasa de dependencia de los hogares ${ }^{b}$ & 0,243 & $0,00 * * *$ & 0,039 & 0,46 & 0,209 & $0,00 * * *$ \\
\hline $\mathrm{N}^{\circ}$ de miembros de 0 a 4 años & 0,042 & $0,00 * * *$ & 0,038 & $0,00 * * *$ & 0,085 & $0,00 * * *$ \\
\hline $\mathrm{N}^{\circ}$ de miembros de 5 a 10 años & 0,031 & $0,01 * * *$ & 0,021 & $0,01 * * *$ & 0,057 & $0,00 * * *$ \\
\hline $\mathrm{N}^{\circ}$ de miembros varones de 11 a 14 años & $-0,014$ & 0,35 & 0,016 & 0,15 & 0,030 & $0,04 * *$ \\
\hline $\mathrm{N}^{\circ}$ de miembros mujeres de 11 a 14 años & 0,023 & 0,13 & 0,013 & 0,25 & 0,030 & $0,04 * *$ \\
\hline $\mathrm{N}^{\circ}$ de miembros varones de 15 a 19 años & 0,014 & 0,47 & 0,009 & 0,54 & 0,044 & $0,02 * *$ \\
\hline $\mathrm{N}^{\circ}$ de miembros mujeres de 15 a 19 años & 0,017 & 0,38 & $-0,020$ & 0,18 & 0,031 & $0,08 *$ \\
\hline $\mathrm{N}^{\circ}$ de miembros varones de 20 a 34 años & 0,009 & 0,56 & 0,018 & 0,12 & 0,028 & $0,05 * *$ \\
\hline $\mathrm{N}^{\circ}$ de miembros mujeres de 20 a 34 años & 0,002 & 0,92 & $-0,010$ & 0,38 & 0,010 & 0,51 \\
\hline $\mathrm{N}^{\circ}$ de miembros varones de 55 años o más & $-0,017$ & 0,47 & $-0,007$ & 0,66 & 0,005 & 0,83 \\
\hline $\mathrm{N}^{\circ}$ de miembros mujeres de 55 años o más & 0,027 & 0,21 & 0,010 & 0,51 & 0,004 & 0,84 \\
\hline $\mathrm{N}^{\circ}$ de asalariados no agrícolas & $-0,009$ & 0,53 & $-0,062$ & $0,00 * * *$ & $-0,044$ & $0,00 * * *$ \\
\hline $\mathrm{N}^{\circ}$ de asalariados agrícolas & 0,028 & $0,02 * *$ & 0,008 & 0,51 & 0,027 & $0,04 * *$ \\
\hline $\mathrm{N}^{\circ}$ que trabaja por cuenta propia & 0,071 & $0,00 * * *$ & $-0,002$ & 0,89 & 0,006 & 0,69 \\
\hline $\mathrm{N}^{\circ}$ que trabaja su propia tierra & 0,028 & $0,03 * *$ & $-0,003$ & 0,79 & 0,003 & 0,79 \\
\hline Vivienda propia & 0,011 & 0,63 & 0,034 & $0,04 * *$ & 0,066 & $0,00 * * *$ \\
\hline Arrendatarios & $-0,076$ & 0,30 & $-0,079$ & 0,18 & $-0,037$ & 0,56 \\
\hline Jefe de hogar trabaja en sector agrícola & 0,070 & $0,02 * *$ & 0,002 & 0,92 & 0,019 & 0,48 \\
\hline Jefe de hogar trabaja en sector manufacturero & 0,029 & 0,50 & $-0,001$ & 0,97 & $-0,012$ & 0,74 \\
\hline Jefe de hogar trabaja en transp. / serv. de utilidad pública / comercio & $-0,041$ & 0,22 & $-0,071$ & $0,00 * * *$ & $-0,031$ & 0,31 \\
\hline Jefe de hogar trabaja en sector público o de defensa & $-0,037$ & 0,50 & $-0,072$ & $0,05 * *$ & $-0,069$ & 0,11 \\
\hline Jefe de hogar trabaja en sector servicios & $-0,035$ & 0,43 & $-0,074$ & $0,01 * * *$ & $-0,007$ & 0,86 \\
\hline Norte & $-0,063$ & $0,00 * * *$ & $-0,079$ & $0,00 * * *$ & $-0,109$ & $0,00 * * *$ \\
\hline Pacífico norte & $-0,121$ & $0,00 * * *$ & $-0,083$ & $0,00 * * *$ & $-0,123$ & $0,00 * * *$ \\
\hline Centro & $-0,061$ & $0,00 * * *$ & $-0,041$ & $0,01 * * *$ & $-0,050$ & $0,01 * * *$ \\
\hline Golfo & $-0,074$ & $0,00 * * *$ & $-0,008$ & 0,66 & $-0,035$ & $0,07 *$ \\
\hline Número de observaciones & & 3927 & & 4801 & & 4438 \\
\hline
\end{tabular}

Fuente: Elaborado por los autores, con datos de la Encuesta nacional de los ingresos y gastos de los hogares (ENIGH) de 1992,1994 y 1996.

a Los coeficientes son probabilidades marginales derivadas de los coeficientes Probit. La categoría excluida respecto del jefe de hogar corresponde a sin educación.

$* * *$ Significativo al $1 \%$.

** Significativo al 5\%

* Significativo al $10 \%$.

b La tasa de dependencia de los hogares corresponde a la razón entre el número de ocupados del hogar y el número total de personas que componen el hogar. 


\section{IV}

\section{La reacción a la crisis}

Para conocer los ajustes que efectuaron los hogares durante la crisis de 1995, investigamos si en el período abarcado por el estudio se habían producido cambios importantes en sus patrones de consumo en general, y del consumo de alimentos en particular. Asimismo, analizamos las tasas de matrícula escolar para comprobar si las familias habían retirado sistemáticamente a sus hijos de la escuela para que contribuyeran al hogar desempeñándose en actividades transitorias que generaran ingresos.

\section{Los patrones de consumo}

Los patrones de consumo se estudiaron de cuatro maneras diferentes, cada una de las cuales sigue en detalle el cuestionario de consumo de la ENIGH. Primero, analizamos las variaciones de las proporciones correspondientes a los principales gastos de consumo en el presupuesto de los hogares, para determinar si en 1995 hubo cambios importantes en esas proporciones para hacer frente al descenso general del bienestar. En seguida, calculamos el efecto-ingreso de las diversas partidas del presupuesto utilizando las ecuaciones de regresión de la curva de Engel. Luego, repetimos ambos ejercicios considerando únicamente la proporción del presupuesto destinada a alimentación.

Las ecuaciones de regresión de la curva de Engel se basan en la fórmula funcional de Working-Leser, mediante la cual se realiza una regresión de la proporción del presupuesto con el logaritmo del gasto total per cápita, el logaritmo del tamaño de la familia, el número de personas pertenecientes a cada uno de 12 grupos de edades por sexo, y el sexo, escolaridad y edad del jefe de hogar: ${ }^{3}$

$w_{\mathrm{i}}=a+b_{1}{ }^{*} \ln (x / n)+b_{2}{ }^{*} \ln (\mathrm{n})+b_{3}{ }^{*} D+b_{4}{ }^{*} H+\mathrm{u}_{\mathrm{i}}$

en que $w$ es la i-ava parte del presupuesto, $x$ es el gasto total del hogar, $n$ es el tamaño del hogar, $D$ es vector de 12 variables demográficas, $H$ es vector de las características del jefe de hogar, y $a$ y $b$ son los parámetros por estimar. En esta fórmula, los valores

\footnotetext{
${ }^{3}$ Para un análisis de esta fórmula funcional, véase Deaton y
} Muellbauer (1980). positivos de $b$ indican bienes suntuarios y los valores negativos corresponden a bienes necesarios.

Comenzamos nuestro análisis de los patrones de consumo con las proporciones del consumo global asignadas a 10 grupos diferentes, que en el cuadro 6 figuran como porcentajes correspondientes a cada uno de los tres años en que se realizó la encuesta. También se muestra la proporción del presupuesto correspondiente al quintil inferior de la distribución del gasto per cápita en cada año. Entre 1994 y 1996 se observa el mismo cambio del patrón de consumo en las zonas urbanas y rurales. El año posterior a la crisis, la proporción del gasto destinada a alimentación se elevó aproximadamente cinco puntos porcentuales, mientras que la proporción destinada a vivienda, bebidas alcohólicas y artículos para el hogar (muebles y artefactos, etc.) se redujo. Asimismo, tanto en las zonas urbanas como en las rurales disminuyó levemente la proporción del presupuesto asignada a vestuario. La caída de la proporción del presupuesto destinada a educación entre 1994 y 1996 resulta preocupante: en las zonas rurales dicha proporción bajó más de 50\% en 1996, y en las zonas urbanas, aproximadamente $25 \%$.

Como era de prever, el quintil más pobre gastó en alimentación una proporción mayor del presupuesto total y entre 1994 y 1996 la variación de esta proporción coincide con la encontrada en el total de la muestra. En las zonas rurales, la proporción destinada a alimentación aumentó siete puntos porcentuales (cuatro en las zonas urbanas), mientras que las proporciones correspondientes a bebidas alcohólicas, vivienda y artículos para el hogar declinaron. En esta submuestra, la baja del gasto en educación, que fue de $70 \%$ en las zonas rurales y de $50 \%$ en las zonas urbanas, es particularmente grande si se la compara con los niveles registrados en 1994.

El cuadro 7 muestra el coeficiente del logaritmo del gasto per cápita calculado a partir de la ecuación [1]. Las estimaciones del efecto-ingreso en las zonas rurales y urbanas indican sin lugar a dudas que la alimentación y la vivienda son bienes necesarios, mientras que la educación, salud e higiene, transporte, artículos para el hogar y transferencias externas son bienes suntuarios. En 1996, tal como era de prever, el 
México: Participación media de los diversos rubros de gasto en el presupuesto de los hogares, zonas rurales y urbanas

(Porcentajes)

\begin{tabular}{|c|c|c|c|c|c|c|}
\hline & \multicolumn{3}{|c|}{ Población total } & \multicolumn{3}{|c|}{ Quintil inferior } \\
\hline & 1992 & 1994 & 1996 & 1992 & 1994 & 1996 \\
\hline \multicolumn{7}{|l|}{ Zonas rurales } \\
\hline Alimentación & 46 & 42 & 47 & 51 & 47 & 54 \\
\hline Bebidas alcohólicas y tabaco & 0 & 3 & 0 & 0 & 1 & 0 \\
\hline Vivienda & 17 & 23 & 22 & 18 & 27 & 25 \\
\hline Transporte y comunicaciones & 7 & 7 & 7 & 3 & 4 & 3 \\
\hline Salud e higiene personal & 6 & 7 & 8 & 4 & 5 & 5 \\
\hline Vestuario y calzado & 8 & 5 & 5 & 10 & 5 & 4 \\
\hline Educación & 2 & 3 & 1 & 2 & 3 & 1 \\
\hline Artículos domésticos & 9 & 8 & 7 & 8 & 7 & 6 \\
\hline Transferencias externas & 1 & 1 & 1 & 0 & 0 & 0 \\
\hline Otros & 5 & 1 & 2 & 4 & 0 & 2 \\
\hline Número de observaciones & 3911 & 4797 & 4442 & 665 & 823 & 814 \\
\hline \multicolumn{7}{|l|}{ Zonas urbanas } \\
\hline Alimentación & 35 & 32 & 36 & 44 & 42 & 46 \\
\hline Bebidas alcohólicas y tabaco & 0 & 2 & 0 & 0 & 1 & 0 \\
\hline Vivienda & 22 & 28 & 26 & 20 & 26 & 24 \\
\hline Transporte y comunicaciones & 8 & 9 & 10 & 6 & 7 & 8 \\
\hline Salud e higiene personal & 6 & 7 & 8 & 6 & 7 & 7 \\
\hline Vestuario y calzado & 5 & 5 & 4 & 6 & 4 & 4 \\
\hline Educación & 5 & 5 & 4 & 5 & 5 & 2 \\
\hline Artículos domésticos & 9 & 7 & 6 & 8 & 7 & 6 \\
\hline Transferencias externas & 2 & 1 & 1 & 0 & 0 & 0 \\
\hline Otros & 8 & 3 & 4 & 6 & 1 & 3 \\
\hline Número de observaciones & 5739 & 7199 & 8709 & 1193 & 1491 & 1979 \\
\hline
\end{tabular}

Fuente: Elaborado por los autores, con datos de la Encuesta nacional de los ingresos y gastos de los hogares (ENIGH) de 1992,1994 y 1996.

coeficiente del gasto en alimentación (en valores absolutos) se elevó significativamente y ese año también se elevaron los coeficientes correspondientes a transporte, vestuario y salud, lo que indica que estos rubros tomaron un carácter más bien suntuario. En 1996, tanto en las zonas urbanas como en las rurales, la vivienda se convirtió en un bien más "suntuario", mientras que en las zonas rurales el incremento de la proporción del gasto destinada a transporte y comunicaciones y a vestuario entre 1994 y 1996 fue particularmente pronunciado.

En las zonas urbanas, la elasticidad-ingreso de los alimentos es menor y lo mismo se aplica al transporte y a la salud y la higiene personal. Además, entre 1994 y 1996 la elasticidad-ingreso de todos estos rubros aumentó en valores absolutos. Una de las diferencias importantes que se observa entre las zonas rurales y las urbanas es la elasticidad-ingreso de la educación, que en las segundas es muy superior (casi el doble). Esto quiere decir que en México el gasto en educación es más sensible al ingreso en las zonas urbanas que en las rurales.

El cuadro 8 muestra los valores medios de la proporción del presupuesto destinada a alimentación en los tres años en estudio. Los desplazamientos entre grupos de alimentos son menores que entre éstos y otros grandes rubros de gasto, pero de todas formas se observan algunos patrones básicos. En las zonas rurales, las familias destinan más de $40 \%$ del presupuesto de alimentación a cereales y a frutas, hortalizas y legumbres, rubros que en el quintil inferior representan alrededor de $60 \%$ del presupuesto alimentario. Durante la crisis, los hogares generalmente reaccionaron aumentando la proporción del gasto destinada a cereales y productos lácteos, y reduciendo a la vez la proporción dedicada a carne y pescado y "otros" alimentos.

Un cambio similar se observa en las zonas urbanas, pese a que los cereales sólo ocuparon el cuarto lugar en el presupuesto para alimentación, mientras que la carne y el pescado y los "alimentos consumidos fuera del hogar" fueron los dos grupos de alimentos de mayor importancia y absorbieron más de $40 \%$ del total del presupuesto para alimentación. Además, los patrones de consumo de los hogares urbanos del quintil inferior se asemejaron más a los de la población rural en su conjunto, con más de $40 \%$ del presupuesto destinado 
CUADRO 7

México: Efecto - ingreso en las proporciones del presupuesto de los hogares ${ }^{a}$

\begin{tabular}{|c|c|c|c|}
\hline & 1992 & 1994 & 1996 \\
\hline \multicolumn{4}{|l|}{ Zonas rurales } \\
\hline Alimentación & $\begin{array}{l}-4,07 \\
(9,82)\end{array}$ & $\begin{array}{c}-5,73 \\
(15,87)\end{array}$ & $\begin{array}{c}-6,55 \\
(16,24)\end{array}$ \\
\hline Bebidas alcohólicas y tabaco & $\begin{array}{c}0,06 \\
(1,09)\end{array}$ & $\begin{array}{c}2,14 \\
(10,52)\end{array}$ & $\begin{array}{c}0,05 \\
(0,92)\end{array}$ \\
\hline Vivienda & $\begin{array}{c}-3,35 \\
(12,18)\end{array}$ & $-6,95$ & $\begin{array}{l}-5,43 \\
(1774)\end{array}$ \\
\hline Transporte y comunicaciones & 3,73 & 1,94 & 3,66 \\
\hline Salud e higiene personal & $\begin{array}{c}(17,16) \\
2,18\end{array}$ & $\begin{array}{c}(9,66) \\
2,50\end{array}$ & $\begin{array}{c}(17,55) \\
3,31\end{array}$ \\
\hline & $(10,81)$ & $(11,54)$ & $(15,40)$ \\
\hline Vestuario y calzado & $-1,48$ & 0,51 & 0,92 \\
\hline Educación & $\begin{array}{c}(7,77) \\
0,45 \\
(3,95)\end{array}$ & $\begin{array}{c}(3,61) \\
0,69 \\
(5,80)\end{array}$ & $\begin{array}{c}(6,89) \\
0,68 \\
(9,13)\end{array}$ \\
\hline Artículos para el hogar & $\begin{array}{c}1,25 \\
(5,45)\end{array}$ & $\begin{array}{c}1,76 \\
(9,22)\end{array}$ & $\begin{array}{c}0,53 \\
(3,70)\end{array}$ \\
\hline Transferencias externas & $\begin{array}{c}0,96 \\
(9,98)\end{array}$ & $\begin{array}{c}2,11 \\
(16,19)\end{array}$ & $\begin{array}{c}1,83 \\
(14,57)\end{array}$ \\
\hline Otros & $\begin{array}{c}0,28 \\
(2,23)\end{array}$ & $\begin{array}{c}1,04 \\
(11,40)\end{array}$ & $\begin{array}{c}1,01 \\
(7,65)\end{array}$ \\
\hline Zonas urbanas & & & \\
\hline Alimentación & $\begin{array}{c}-8,04 \\
(27,82)\end{array}$ & $\begin{array}{c}-8,65 \\
(37,21)\end{array}$ & $\begin{array}{c}-9,26 \\
(38,35)\end{array}$ \\
\hline Bebidas alcohólicas y tabaco & $\begin{array}{c}0,04 \\
(1,54)\end{array}$ & $\begin{array}{c}1,12 \\
(8,05)\end{array}$ & $\begin{array}{l}-0,01 \\
(0,25)\end{array}$ \\
\hline Vivienda & $\begin{array}{l}-1,30 \\
(5,07)\end{array}$ & $\begin{array}{c}-2,99 \\
(11,09)\end{array}$ & $\begin{array}{l}-1,56 \\
(6,75)\end{array}$ \\
\hline Transporte y comunicaciones & $\begin{array}{c}1,16 \\
(7,36)\end{array}$ & $\begin{array}{c}0,81 \\
(5,82)\end{array}$ & $\begin{array}{c}1,19 \\
(8,44)\end{array}$ \\
\hline Salud e higiene personal & $\begin{array}{l}1,12 \\
(8,42)\end{array}$ & $\begin{array}{c}1,78 \\
(10,87)\end{array}$ & $\begin{array}{c}2,41 \\
(15,65)\end{array}$ \\
\hline Vestuario y calzado & $\begin{array}{c}0,38 \\
(3,60)\end{array}$ & $\begin{array}{c}0,22 \\
(2,43)\end{array}$ & $\begin{array}{c}0,61 \\
(7,78)\end{array}$ \\
\hline Educación & $\begin{array}{l}1,30 \\
(8,45)\end{array}$ & $\begin{array}{c}1,75 \\
(11,96)\end{array}$ & $\begin{array}{c}1,94 \\
(17,96)\end{array}$ \\
\hline Artículos para el hogar & $\begin{array}{c}2,09 \\
(11,54)\end{array}$ & $\begin{array}{c}1,69 \\
(11,38)\end{array}$ & $\begin{array}{c}0,65 \\
(6,73)\end{array}$ \\
\hline Transferencias externas & $\begin{array}{r}1,89 \\
(17,93)\end{array}$ & $\begin{array}{c}1,30 \\
(14,41)\end{array}$ & $\begin{array}{c}1,36 \\
(16,37)\end{array}$ \\
\hline Otros & $\begin{array}{c}1,37 \\
(8,46)\end{array}$ & $\begin{array}{c}2,96 \\
(27,26)\end{array}$ & $\begin{array}{c}2,66 \\
(23,18)\end{array}$ \\
\hline
\end{tabular}

Fuente: Elaborado por los autores, con datos de la Encuesta nacional de los ingresos y gastos de los hogares (ENIGH) de 1992,1994 y 1996.

a Las cifras corresponden a coeficientes del logaritmo del gasto per cápita derivado de estimaciones de la curva de Engel utilizando la ecuación [1] que figura en el texto. Las estadísticas $t$ aparecen entre paréntesis, debajo de los coeficientes. Los coeficientes negativos indican consumo necesario; los positivos indican consumo suntuario.

a cereales y a hortalizas, frutas y legumbres.

El cuadro 9 contiene estimaciones de la elasticidadingreso de cada grupo de alimentos por año y en zonas urbanas y rurales, que se obtuvieron mediante la ecuación [1]. Tanto en las zonas urbanas como en las rurales, los cereales, hortalizas y "otros" alimentos fueron claramente bienes necesarios, mientras que los alimentos consumidos fuera del hogar fueron más bien suntuarios. Sin embargo, la carne y el pescado sólo constituyeron bienes suntuarios en las zonas rurales, mientras que en las zonas urbanas los productos lácteos fueron una necesidad. Entre 1994 y 1996 se observa un incremento (en valores absolutos) de la elasticidad-ingreso de los cereales y de las hortalizas (es decir, pasaron a aumentar su carácter de bienes necesarios), mientras que "otros" alimentos se convirtieron en un lujo (disminuyó su elasticidad-ingreso). Curiosamente, en 1996 bajó la elasticidad- ingreso de los alimentos consumidos fuera del hogar.

\section{La matrícula escolar}

Los datos de la ENIGH no arrojan muchas luces sobre resultados individuales en materia de bienestar, como los de salud o nutrición. La información sobre los logros educativos, incluidos los datos sobre la matrícula 
CUADRO 8

México: Participaciones medias de diferentes rubros de gasto en el presupuesto de alimentación de los hogares

(Porcentajes)

\begin{tabular}{|c|c|c|c|c|c|c|}
\hline & \multicolumn{3}{|c|}{ Población total } & \multicolumn{3}{|c|}{ Quintil inferior } \\
\hline & 1992 & 1994 & 1996 & 1992 & 1994 & 1996 \\
\hline \multicolumn{7}{|l|}{ Zonas rurales } \\
\hline Carne y pescado & 14 & 16 & 15 & 8 & 12 & 10 \\
\hline Productos lácteos & 14 & 14 & 15 & 13 & 13 & 12 \\
\hline Vegetales, frutas y legumbres & 24 & 21 & 21 & 32 & 27 & 27 \\
\hline Preparación de alimentos & 2 & 2 & 1 & 1 & 1 & 1 \\
\hline Otros alimentos & 11 & 13 & 12 & 11 & 14 & 12 \\
\hline Número de observaciones & 3911 & 4797 & 4442 & 665 & 823 & 814 \\
\hline \multicolumn{7}{|l|}{ Zonas urbanas } \\
\hline Cereales & 13 & 13 & 15 & 21 & 20 & 23 \\
\hline Carne y pescado & 23 & 23 & 21 & 22 & 22 & 18 \\
\hline Productos lácteos & 15 & 15 & 17 & 17 & 17 & 19 \\
\hline Alimentos consumidos fuera del hogar & 21 & 21 & 19 & 8 & 8 & 8 \\
\hline Otros alimentos & 8 & 9 & 8 & 9 & 9 & 9 \\
\hline Número de observaciones & 5739 & 7199 & 8709 & 1193 & 1491 & 1979 \\
\hline
\end{tabular}

Fuente: Elaborado por los autores, con datos de la Encuesta nacional de los ingresos y gastos de los hogares (ENIGH) de 1992,1994 y 1996.

CUADRO 9

México: Efecto - ingreso en el consumo de alimentos ${ }^{a}$

\begin{tabular}{|c|c|c|c|}
\hline & 1992 & 1994 & 1996 \\
\hline \multicolumn{4}{|l|}{ Zonas rurales } \\
\hline Cereales & $\begin{array}{c}-8,29 \\
(20,72)\end{array}$ & $\begin{array}{c}-8,15 \\
(22,32)\end{array}$ & $\begin{array}{c}-8,71 \\
(22,04)\end{array}$ \\
\hline Carne y pescado & $\begin{array}{c}5,90 \\
(14,37)\end{array}$ & $\begin{array}{c}4,48 \\
(11,40)\end{array}$ & $\begin{array}{r}5,38 \\
(13,71)\end{array}$ \\
\hline Productos lácteos & $\begin{array}{c}-0,32 \\
(0,89)\end{array}$ & $\begin{array}{c}10,35 \\
(1,15)\end{array}$ & $\begin{array}{c}0,50 \\
(1.57)\end{array}$ \\
\hline Hortalizas, frutas y legumbres & $\begin{array}{r}-6,89 \\
(17,35)\end{array}$ & $\begin{array}{c}-6,28 \\
(17,75)\end{array}$ & $\begin{array}{r}-6,42 \\
(17,93)\end{array}$ \\
\hline Preparación de alimentos & $\begin{array}{c}1,05 \\
(5,19)\end{array}$ & $\begin{array}{c}0,81 \\
(6,02)\end{array}$ & $\begin{array}{c}0,50 \\
(3,48)\end{array}$ \\
\hline Alimentos consumidos fuera del hogar & $\begin{array}{r}9,60 \\
(17,21)\end{array}$ & $\begin{array}{c}10,84 \\
118,89)\end{array}$ & $\begin{array}{r}9,40) \\
9,38 \\
(15,83)\end{array}$ \\
\hline Otros alimentos & $\begin{array}{c}-1,06 \\
(3,80)\end{array}$ & $\begin{array}{c}-1,36 \\
(4,51)\end{array}$ & $\begin{array}{c}-0,62 \\
(2,22)\end{array}$ \\
\hline Zonas urbanas & & & \\
\hline Cereales & $\begin{array}{c}-5,48 \\
(27,51)\end{array}$ & $\begin{array}{c}-5,29 \\
(30,46)\end{array}$ & $\begin{array}{c}-5,68 \\
(31,24)\end{array}$ \\
\hline Carne y pescado & $\begin{array}{c}-0,42 \\
(1,21)\end{array}$ & $\begin{array}{r}-0,59 \\
(1,92)\end{array}$ & $\begin{array}{c}0,34 \\
(1,20)\end{array}$ \\
\hline Productos lácteos & $\begin{array}{c}-2,41 \\
(10,25)\end{array}$ & $\begin{array}{c}-2,57 \\
(12,22)\end{array}$ & $\begin{array}{l}-1,90 \\
(9,22)\end{array}$ \\
\hline Hortalizas, frutas y legumbres & $\begin{array}{r}-4,20 \\
(16,76)\end{array}$ & $\begin{array}{c}-4,23 \\
(1983)\end{array}$ & $\begin{array}{c}-3,61 \\
(18,51)\end{array}$ \\
\hline Preparación de alimentos & $\begin{array}{c}0,81 \\
(4,12)\end{array}$ & $\begin{array}{c}0,66 \\
(4,14)\end{array}$ & $\begin{array}{r}0,59 \\
(3,85)\end{array}$ \\
\hline Alimentos consumidos fuera del hogar & $\begin{array}{c}12,46 \\
(21,95)\end{array}$ & $\begin{array}{c}12,54 \\
(23,63)\end{array}$ & $\begin{array}{c}10,60 \\
(22,43)\end{array}$ \\
\hline Otros alimentos & $\begin{array}{c}-0,77 \\
(4,23)\end{array}$ & $\begin{array}{c}(2,0,51 \\
(2,98)\end{array}$ & $\begin{array}{c}-0,35 \\
(2,25)\end{array}$ \\
\hline
\end{tabular}

Fuente: Elaborado por los autores, con datos de la Encuesta nacional de los ingresos y gastos de los hogares (ENIGH) de 1992,1994 y 1996.

a Las cifras son coeficientes del logaritmo del gasto per cápita derivado de las estimaciones de la curva de Engel, utilizando la ecuación [1] que figura en el texto. Las estadísticas $t$ aparecen entre paréntesis, debajo de los coeficientes. Los coeficientes negativos indican consumo necesario; los positivos indican consumo suntuario. 
escolar, ayuda a comprender mejor las posibles estrategias de los hogares mexicanos para hacer frente a la crisis. En general, las tasas de matrícula son elevadas $(90 \%)$ hasta el término de la enseñanza primaria y comienzan a caer alrededor de los 11 años, por lo cual centramos la atención en el grupo de edades de 12 a 15 años y analizamos los patrones de matrícula para ver si la crisis de 1995 afectó de manera significativa el posible desarrollo a largo plazo mediante la baja de las tasas de matrícula escolar.

El cuadro 10 muestra las tasas medias de matrícula, en regiones urbanas y rurales y por sexo del niño, tanto respecto del total de la muestra como de los niños que vivían en hogares ubicados en el quintil inferior de la distribución del gasto per cápita en cada año. En general, en las zonas urbanas las tasas fueron más elevadas que en las zonas rurales, y entre los varones que entre las niñas. El papel del ingreso parece haber sido más marcado en las zonas urbanas, conclusión que coincide con la mayor elasticidad-ingreso de los gastos en educación de las zonas urbanas, antes indicada. La diferencia entre el total de la muestra y el quintil inferior fue mayor en las zonas urbanas (20 puntos porcentuales en el caso de las niñas) que en las zonas rurales (la diferencia entre varones y mujeres nunca superó los 10 puntos porcentuales), diferencia que aumentó en 1996. Tanto en las zonas urbanas como en las rurales la matrícula masculina permaneció estable, pese a la leve baja registrada después de la crisis. De acuerdo con lo observado en el cuadro 10, el grupo más afectado en materia de matrícula fue el de las niñas del quintil inferior de las zonas urbanas. En este grupo la tasa de matrícula cayó 14 puntos porcentuales entre 1994 y $1996 \mathrm{y}$, de hecho, en 1996 fue inferior (46\%) que al comienzo del período en estudio (61\%).

Este resultado se confirma en un contexto de variables múltiples. Reunimos los datos de las encuestas correspondientes a los tres años y estimamos una ecuación Probit para la probabilidad de que la persona hubiera estado matriculada en la escuela en el momento de la encuesta. Las variables de control utilizadas en este ejercicio incluyeron la edad y sexo del niño, el nivel educativo y sexo del jefe de hogar, el logaritmo del gasto per cápita del hogar y el año de la encuesta. Incluimos una variable ficticia igual a 1 para el caso de que en 1996 se tratara de una niña perteneciente al quintil inferior. En las zonas urbanas el coeficiente de esta variable resultó significativo y al evaluarlo en su valor medio, puso de manifiesto que la tasa de matrícula de las niñas de las familias más pobres era 7 puntos porcentuales más baja que la de los demás niños encuestados. En las zonas rurales, este coeficiente no resultó significativo. ${ }^{4}$

Tal como lo hicimos antes en el caso de los patrones de consumo, estimamos modelos Probit respecto de los factores que determinan las tasas de matrícula,

CUADRO 10

México: Tasa media de matrícula escolar de niños de 12 a 15 años, por año y por sexo (Porcentajes)

\begin{tabular}{|c|c|c|c|c|c|c|}
\hline & \multicolumn{2}{|c|}{1992} & \multicolumn{2}{|c|}{1994} & \multicolumn{2}{|c|}{1996} \\
\hline & Varones & Mujeres & Varones & Mujeres & Varones & Mujeres \\
\hline Zonas rurales & 67 & 57 & 66 & 63 & 68 & 63 \\
\hline Quintil inferior & 64 & 48 & 63 & 60 & 57 & 55 \\
\hline Zonas urbanas & 84 & 81 & 88 & 81 & 88 & 82 \\
\hline Quintil inferior & 65 & 61 & 76 & 60 & 68 & 46 \\
\hline
\end{tabular}

Fuente: Elaborado por los autores, con datos de la Encuesta nacional de los ingresos y gastos de los hogares (ENIGH) de 1992,1994 y 1996.

separadamente para cada año y para zonas urbanas y rurales, a fin de establecer en qué medida podrían haber variado como consecuencia de la crisis económica de 1995. Las variables de control fueron las antes mencionadas (salvo las variables ficticias correspondientes al año de la encuesta), aunque en el caso de las zonas rurales tuvimos que utilizar una menor cantidad de variables ficticias para el nivel educativo del jefe de hogar, en atención al reducido tamaño de los casilleros.

En el cuadro 11 figuran las probabilidades marginales del modelo Probit derivadas de las estimaciones de los coeficientes subyacentes. Nos interesaba en especial el patrón del "efecto-ingreso"

\footnotetext{
${ }^{4}$ Los resultados pueden solicitarse a los autores.
} 
en el tiempo y las diferencias entre varones y mujeres. Como era de esperar, entre 1994 y 1996 aumentó el efecto-ingreso aunque, en la práctica, inmediatamente después de la crisis se redujo la diferencia entre varones y mujeres. Es posible que esto se haya debido a que durante la crisis los niños fueron retirados más rápidamente de la escuela que las niñas. Cabe también señalar que en 1996 la rentabilidad del nivel educativo del jefe de hogar no siempre se incrementó, como podría haberse esperado (el coeficiente se eleva en el caso de la enseñanza primaria pero baja en el de la enseñanza secundaria), lo que indica que el descenso de la matrícula que se produjo en 1996 no dependió del nivel educativo del jefe de hogar.

En las zonas urbanas, el efecto-ingreso fue aproximadamente igual al de las zonas rurales, con un aumento entre 1994 y 1996. Sin embargo, en las zonas urbanas la "ventaja" de los varones fue menor y entre

CUADRO 11

México: Estimaciones Probit de los factores determinantes de la matrícula escolar de niños de 12 a 15 años ${ }^{a}$

\begin{tabular}{|c|c|c|c|}
\hline & $\begin{array}{c}(1) \\
1992 \\
\end{array}$ & $\begin{array}{c}(2) \\
1994 \\
\end{array}$ & $\begin{array}{c}(3) \\
1996 \\
\end{array}$ \\
\hline \multicolumn{4}{|l|}{ Zonas rurales } \\
\hline Log del gasto per cápita & $\begin{array}{c}0,074 \\
(4,57)\end{array}$ & $\begin{array}{c}0,097 \\
(6,27)\end{array}$ & $\begin{array}{r}0,114 \\
(6,98)\end{array}$ \\
\hline Niño varón & $\begin{array}{c}0,090 \\
(4,22)\end{array}$ & $\begin{array}{c}0,082 \\
(4,28)\end{array}$ & $\begin{array}{r}0,055 \\
(2,83)\end{array}$ \\
\hline 13 años de edad & $\begin{array}{l}-0,135 \\
(4,33)\end{array}$ & $\begin{array}{l}-0,231 \\
(7,74)\end{array}$ & $\begin{array}{l}-0,149 \\
(4,92)\end{array}$ \\
\hline 14 años de edad & $\begin{array}{l}-0,282 \\
(9,17)\end{array}$ & $\begin{array}{r}-0,354 \\
(12,06)\end{array}$ & $\begin{array}{l}-0,274 \\
(9,17)\end{array}$ \\
\hline 15 años de edad & $\begin{array}{r}-0,484 \\
(15,69)\end{array}$ & $\begin{array}{c}-0,511 \\
(17,41)\end{array}$ & $\begin{array}{r}-0,470 \\
(15,47)\end{array}$ \\
\hline Jefe de hogar es mujer & $\begin{array}{l}-0,036 \\
(0,83)\end{array}$ & $\begin{array}{l}-0,082 \\
(2,30)\end{array}$ & $\begin{array}{c}0,008 \\
(0,21)\end{array}$ \\
\hline Jefe de hogar tiene enseñanza primaria incompleta & $\begin{array}{c}0,055 \\
(2,28)\end{array}$ & $\begin{array}{c}0,020 \\
(0,94)\end{array}$ & $\begin{array}{r}0,034 \\
(1,44)\end{array}$ \\
\hline Jefe de hogar tiene enseñanza primaria completa & $\begin{array}{c}0,152 \\
(4,51)\end{array}$ & $\begin{array}{c}0,076 \\
(2,49)\end{array}$ & $\begin{array}{r}0,111 \\
(3,85)\end{array}$ \\
\hline Jefe de hogar tiene algunos estudios secundarios & $\begin{array}{c}0,272 \\
(5,45)\end{array}$ & $\begin{array}{c}0,183 \\
(4,01)\end{array}$ & $\begin{array}{r}0,145 \\
(3,41) \\
\end{array}$ \\
\hline $\mathrm{N}^{\mathrm{o}}$ de observaciones & 2226 & 2632 & 2417 \\
\hline \multicolumn{4}{|l|}{ Zonas urbanas } \\
\hline Log del gasto per cápita & $\begin{array}{c}0,083 \\
(7,46)\end{array}$ & $\begin{array}{c}0,080 \\
(8,23)\end{array}$ & $\begin{array}{r}0,092 \\
(9,91)\end{array}$ \\
\hline Niño varón & $\begin{array}{c}0,034 \\
(2,61)\end{array}$ & $\begin{array}{c}0,048 \\
(4,09)\end{array}$ & $\begin{array}{r}0,048 \\
(4,49)\end{array}$ \\
\hline 13 años de edad & $\begin{array}{l}-0,111 \\
(4,44)\end{array}$ & $\begin{array}{l}-0,093 \\
(4,12)\end{array}$ & $\begin{array}{l}-0,068 \\
(3,46)\end{array}$ \\
\hline 14 años de edad & $\begin{array}{l}-0,163 \\
(6,54)\end{array}$ & $\begin{array}{l}-0,176 \\
(7,75)\end{array}$ & $\begin{array}{l}-0,175 \\
(8,48)\end{array}$ \\
\hline 15 años de edad & $\begin{array}{c}-0,343 \\
(13,00)\end{array}$ & $\begin{array}{c}-0,339 \\
(13,33)\end{array}$ & $\begin{array}{r}-0,272 \\
(12,33)\end{array}$ \\
\hline Jefe de hogar es mujer & $\begin{array}{l}-0,063 \\
(3,11)\end{array}$ & $\begin{array}{l}-0,029 \\
(1,67)\end{array}$ & $\begin{array}{l}-0,022 \\
(1,40)\end{array}$ \\
\hline Jefe de hogar tiene enseñanza primaria incompleta & $\begin{array}{r}0,060 \\
(3,50)\end{array}$ & $\begin{array}{c}0,052 \\
(3,45)\end{array}$ & $\begin{array}{r}0,024 \\
(1,58)\end{array}$ \\
\hline Jefe de hogar tiene enseñanza primaria completa & $\begin{array}{c}0,119 \\
(7,08)\end{array}$ & $\begin{array}{c}0,087 \\
(5,72)\end{array}$ & $\begin{array}{r}0,065 \\
(4,23)\end{array}$ \\
\hline Jefe de hogar tiene algunos estudios secundarios & $\begin{array}{c}0,118 \\
(6,60)\end{array}$ & $\begin{array}{c}0,121 \\
(7,48)\end{array}$ & $\begin{array}{c}0,080 \\
(4,84)\end{array}$ \\
\hline Jefe de hogar tiene alguna educación técnica o vocacional & $\begin{array}{c}0,101 \\
(4,16)\end{array}$ & $\begin{array}{c}0,105 \\
(4,72)\end{array}$ & $\begin{array}{r}0,104 \\
(5,02)\end{array}$ \\
\hline Jefe de hogar tiene alguna educación superior & $\begin{array}{c}0,106 \\
(4,14)\end{array}$ & $\begin{array}{c}0,094 \\
(4,12)\end{array}$ & $\begin{array}{r}0,076 \\
(3,43) \\
\end{array}$ \\
\hline $\mathrm{N}^{\mathrm{o}}$ de observaciones & 2658 & 3126 & 3554 \\
\hline
\end{tabular}

Fuente: Elaborado por los autores, con datos de la Encuesta nacional de los ingresos y gastos de los hogares (ENIGH) de 1992,1994 y 1996.

a El valor absoluto de las estadísticas $z$ figura entre paréntesis. Los coeficientes son probabilidades marginales derivadas de los coeficientes Probit. La categoría excluida respecto del nivel educativo del jefe de hogar corresponde a sin educación. 
1994 y 1996 se mantuvo invariable. Un resultado de particular interés es el hecho de que entre 1994 y 1996 disminuyera la rentabilidad del nivel educativo del jefe de hogar. Por lo tanto, la caída de la matrícula que se produjo como consecuencia de la crisis siempre estuvo relacionada con el nivel educativo del jefe de hogar, pero en sentido contrario a lo que cabría haber esperado. Sin embargo, la deserción escolar efectivamente guardó relación con el bienestar general de la familia (medido por el gasto per cápita) y las probabilidades de que la tasa de matrícula de los hogares más pobres descendiera fueron superiores en 1996 que en 1994.

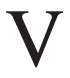

\section{Análisis con técnicas de descomposición}

La acentuada caída del consumo privado que se produjo tras la crisis tuvo lugar inmediatamente después de un período de expansión económica y de vigoroso aumento del consumo, y luego de casi dos decenios de crecientes avances en los indicadores del capital humano (por ejemplo, logros en materia de educación y de salud) y el correspondiente descenso de las tasas de pobreza. Antes de que se desencadenara la crisis, la sociedad mexicana era ya sin duda muy distinta de lo que había sido 15 años antes, pues habían cambiado las características de la población y la estructura de la economía. Pese a ello, casi de la noche a la mañana el consumo privado y la pobreza retrocedieron a los niveles que habían registrado tres lustros antes. ¿Hasta qué punto la evolución de las características de los hogares mexicanos influyó en su capacidad de absorber el shock económico de 1995, y de recuperarse posteriormente? En la presente sección aplicamos técnicas de descomposición para tratar de comprender el papel que desempeñaron las reformas estructurales orientadas al desarrollo a largo plazo (como los cambios en la economía y la expansión del capital humano) en el período de crisis económica, y cuáles fueron exactamente las características de los hogares asociadas a la disminución del bienestar durante la crisis.

Para cada uno de los años a que se refieren las encuestas relacionamos el consumo per cápita de los hogares (en forma de logaritmo) con un conjunto de características de los hogares, las que clasificamos en siete grupos:

$$
\begin{aligned}
\log \mathrm{C}_{\mathrm{i}}= & \alpha+\beta_{1}{ }^{*} \mathrm{MISC}+\beta_{2}{ }^{*} \mathrm{HE}+\beta_{3}{ }^{*} \mathrm{NHE}+\beta_{4}{ }^{*} \text { DEMO }+ \\
& \beta_{5}{ }^{*} \mathrm{EMPL}+\beta_{6}{ }^{*} \mathrm{HOUSE}+\beta_{7}{ }^{*} \mathrm{SECTOR}+\mathrm{u}_{\mathrm{i}}[2]
\end{aligned}
$$

en que:

MISC es un conjunto de variables heterogéneas que incluye el logaritmo del tamaño de la familia, y el sexo y edad del jefe de hogar.

HE es el nivel educativo del jefe de hogar y se mide por un conjunto de nueve variables ficticias que indican distintos niveles de escolaridad.

NHE es el nivel educativo de los no jefes de hogar, medido por el número de miembros del hogar en cada uno de cuatro niveles diferentes de escolaridad.

DEMO $^{5}$ es el número de personas pertenecientes a cada uno de 10 grupos etarios diferentes, clasificados por sexo, más la relación de dependencia del hogar.

EMPL es el número de personas que trabajaban, respectivamente, como asalariados agrícolas, asalariados no agrícolas, por cuenta propia y en empleo familiar.

HOUSE se capta mediante dos variables ficticias que indican si el hogar es dueño o arrendatario de la vivienda que ocupa (la categoría excluida comprende los demás tipos de tenencia).

SECTOR es el sector de empleo en que se desempeña el jefe de hogar.

En la ecuación [2], los valores de $a$ y de las $b$ son los parámetros por estimar y $u_{i}$ es un término de error aleatorio. La ecuación [2] se estima respecto de los hogares, separadamente por año y por zonas urbanas y rurales. Utilizando las estimaciones relativas a las zonas rurales y urbanas correspondientes a años

\footnotetext{
5 Las regresiones no incluyen el número de varones y mujeres de 36 a 50 años debido a que está directamente correlacionado con el número de adultos no jefes de hogar en los cuatro grupos de escolaridad, así como el número de adultos en cada uno de los cuatro sectores de empleo.
} 
adyacentes, descomponemos la variación del consumo entre años en la proporción correspondiente a variaciones del nivel medio de las características del hogar y la proporción atribuible a diferencias de rentabilidad de estas características -los coeficientes beta-, aplicando estrictamente la técnica introducida por Ronald Oaxaca (1973 y 1998). Así, por ejemplo, la descomposición entre 1992 y 1994, usando 1992 como período base, puede escribirse como sigue: $\triangle \operatorname{Con}=\operatorname{Con}_{92}-\operatorname{Con}_{94}=\left(C_{92}-C_{94}\right)+\bar{X}_{94} *\left(\hat{\beta}_{92}-\hat{\beta}_{94}\right)$
$+\hat{\beta}_{92} *\left(\bar{X}_{92}-\bar{X}_{94}\right)$

siendo Con el logaritmo del consumo per cápita, $C_{i}$ el término constante de la regresión correspondiente al período $i, \bar{X}_{i}$ la media de las características de los hogares en el período $i$, y $\hat{\beta}_{i}$ el coeficiente del vector correspondiente a la regresión a partir del período $i$. De acuerdo con la ecuación [3], la variación del consumo entre 1992 y 1994 puede ser descompuesta en tres elementos. El primero de ellos es la diferencia del término constante estimado entre ambos períodos. El segundo es la diferencia entre los dos períodos de los coeficientes beta que representan la rentabilidad de las características de los hogares. El tercero es la diferencia de las características de los hogares entre los dos períodos, es decir, la variación en la dotación de esas características. Puesto que los valores del período inicial se sustraen de los correspondientes al período siguiente, un aumento del consumo entre los dos períodos se reflejará en una variación negativa del consumo en el lado izquierdo de la ecuación [3]. Como veremos, eso es lo que ocurrió entre 1992 y 1994. De manera similar, una disminución del consumo se traducirá en una variación positiva en el lado izquierdo de la ecuación [3], como ocurrió entre 1994 y 1996.

Tradicionalmente, esta técnica para desglosar los factores se aplica a las diferencias de salario entre hombres y mujeres; en ese contexto, la proporción de la diferencia de salario que corresponde a diferencias en los coeficientes beta (es decir, en la rentabilidad de las características) es una medida del tratamiento desigual que reciben varones y mujeres en el mercado de trabajo. En nuestro estudio comparamos las diferencias de consumo en el tiempo, por lo cual las diferencias entre los coeficientes beta pueden interpretarse como diferencias del entorno entre ambos lapsos de tiempo, que se traducen en rentabilidades diferentes de características tales como el nivel educativo y el sector de empleo del jefe de hogar, por ejemplo. Además, pese a que nos referiremos a los cambios en las variables $X$ como a cambios en las características del hogar, es importante destacar que a corto plazo algunas de estas variaciones son endógenas, ya que frente a una crisis económica las familias pueden separarse o unirse, o bien el jefe de hogar puede cambiar de sector de empleo. A corto plazo, el conjunto de variables que tiene más probabilidades de ser exógeno es el que describe el nivel educativo del jefe de hogar y de otros adultos que miembros de él, y como ellos son una medida directa del capital humano, prestamos especial atención a la contribución de estas variables a los cambios en el consumo global del hogar.

Dentro de este marco, desarrollamos una serie de hipótesis y supuestos previos respecto de la fuente y magnitud de las variaciones del consumo entre 1992 y 1994 y entre 1994 y 1996. Primero, esperamos que las variaciones de los coeficientes beta explicaran la mayor parte de las modificaciones del consumo, porque a corto plazo las variables $X$ que utilizamos generalmente no fluctúan demasiado, y nuestro marco cronológico sólo abarca cuatro años. Sin embargo, debido a la crisis económica, esperamos que una proporción mayor de la variación del consumo entre 1994 y 1996 se explique por los cambios de los coeficientes beta respecto del período 1992-1994.

Segundo, como ya se dijo, la crisis de 1995 fue precedida por un prolongado período de expansión del capital humano, así como de reestructuración económica. Si los cambios consiguientes en las características de la población mexicana se tradujeron en incrementos del consumo, nuestro análisis debería mostrar en las características de $X$ modificaciones que llevarían a incrementar el consumo en el tiempo, aunque no en gran magnitud debido a que el período estudiado es de sólo cuatro años.

Además de estas hipótesis principales, el desglose nos permite determinar cuál fue el grupo de características del hogar que más contribuyó al descenso (o aumento) del consumo en el período estudiado. Finalmente, podemos usar los coeficientes estimados para 1996, junto con las características $X$ en 1992, a fin de simular y cuantificar el papel que desempeñaron las reformas estructurales asociadas al proceso de desarrollo a largo plazo, medido por los rasgos de las variables $X$, en paliar las consecuencias adversas de las perturbaciones macroeconómicas.

El cuadro 12 muestra los resultados del análisis de los factores respecto de las zonas rurales y urbanas en los dos períodos adyacentes. ${ }^{6}$ En cada caso se utiliza

${ }^{6}$ Los resultados totales de las regresiones pueden solicitarse a los autores. 
como base el consumo en el período inicial. Entre 1992 y 1994 éste aumentó, de modo que las diferencias resultaron negativas, mientras que entre 1994 y 1996 el consumo se redujo, por lo cual las diferencias fueron positivas. Los resultados indican que entre 1992 y 1994, un 95\% del aumento del consumo obedeció a variaciones en la rentabilidad de las características del hogar (incluido el término constante) y $5 \%$ a la mejora de estas características. Sin embargo, entre 1994 y 1996 las variaciones de rentabilidad originaron 106\% de la baja del consumo, mientras que el mejoramiento de las características $X$ se tradujo de hecho en un aumento del consumo de $6 \%$. Otro tanto sucede con los resultados correspondientes a las zonas urbanas. Las variaciones de los coeficientes beta explicaron una proporción mayor del cambio en el consumo registrado entre el período 1994-1996 y el anterior, y las variaciones de las características $X$ aumentaron la capacidad de las familias de generar consumo, particularmente entre 1994 y 1996.

Las características exactas que contribuyeron a generar cambios positivos del consumo son distintas según el período de tiempo y según si se trata de zonas urbanas o rurales. En estas últimas, las características demográficas de los hogares explicaron la mayor parte del aumento del consumo en las variables $X$ que se produjo en el primer período, mientras que en el segundo los aportes más importantes correspondieron al nivel educativo del jefe de hogar $(2,6 \%)$ y de los no jefes de hogar $(1,27 \%)$. En las zonas urbanas, los aportes positivos al consumo en el segundo período correspondieron al nivel educativo del jefe de hogar $(2,24 \%)$ y a la categoría "otros" $(1,40 \%)$, específicamente el tamaño del hogar. Naturalmente, la mayor parte de los cambios en el consumo derivó de variaciones en la rentabilidad de estas características. En el período 1992-1994, los grandes cambios experimentados por la rentabilidad del tipo de empleo y la composición demográfica mejoraron significativamente el consumo del hogar, y fue precisamente la baja de la rentabilidad de estas dos características lo que condujo a la acentuada caída del consumo durante la crisis.

México: Descomposición de la variación del consumo (Variación porcentual)

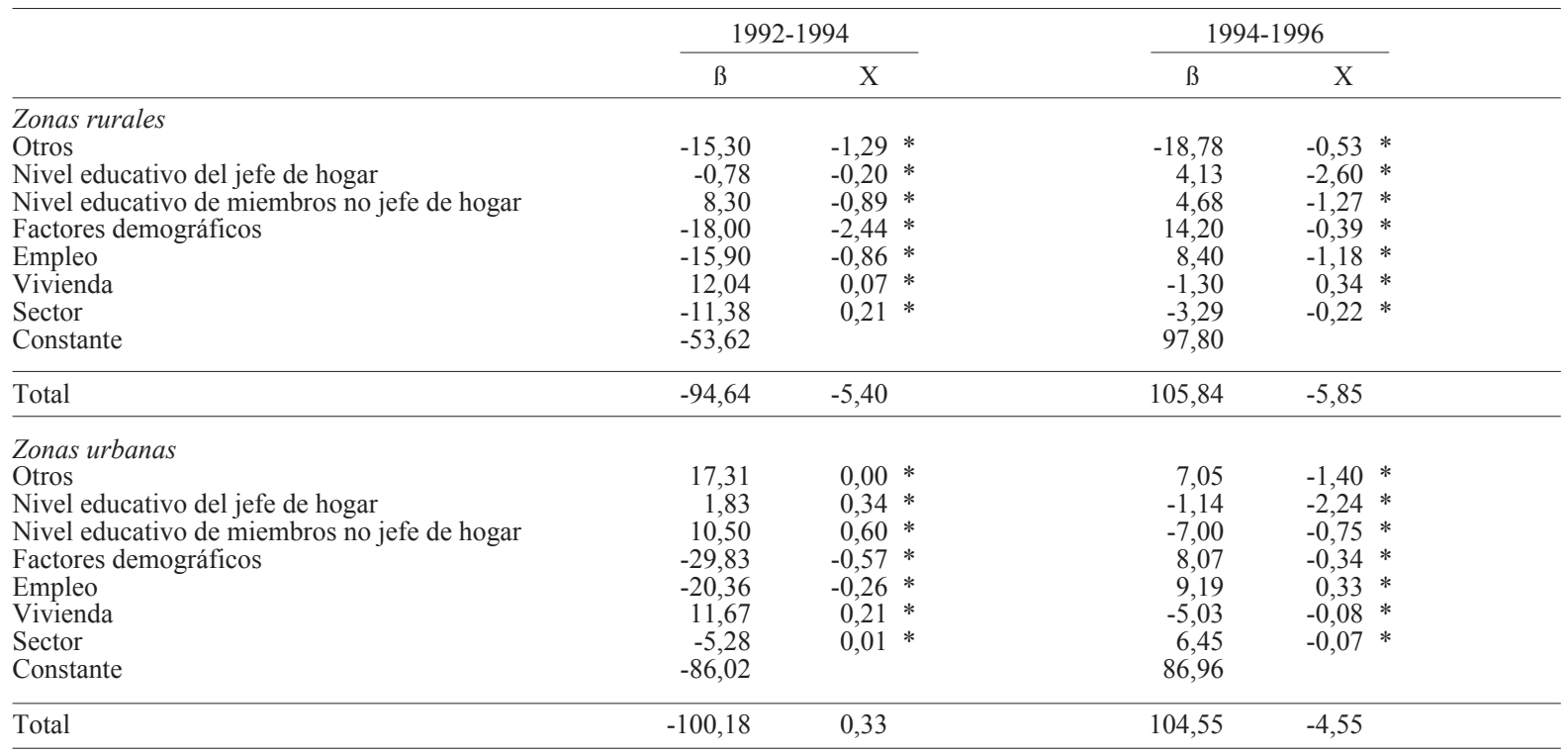

Fuente: Elaborado por los autores, con datos de la Encuesta nacional de los ingresos y gastos de los hogares (ENIGH) de 1992,1994 y 1996.

* Significación conjunta a nivel de $1 \%$. 
En México, el grado de desarrollo económico varía mucho de una región a otra; por lo tanto, es posible que la crisis de 1995 haya afectado de manera diferente a las distintas regiones. Para evaluar esta hipótesis dividimos el país en seis regiones ${ }^{7} \mathrm{y}$ repetimos para cada una de ellas el análisis con técnicas de descomposición. Los resultados por período figuran en el cuadro 13.

En todas las regiones, la proporción del cambio en el consumo atribuible a variaciones de beta fue mayor en el período de crisis (1994-1996). Además, en este mismo período todas las regiones, salvo la del Pacífico sur, acusaron variaciones de las características $X$ que contribuyeron a aumentar el consumo en el período 1994-1996 y, en consecuencia, redujeron o paliaron los efectos negativos del cambio de rentabilidad de esas características. Estos efectos positivos para la dotación de características fueron particularmente marcados en la región del Golfo (13,6 \%) y en el Centro $(7,6 \%)$. En ambos casos, las causas del mejoramiento fueron el nivel educativo del jefe de hogar y la categoría "otros" (en especial el tamaño de la familia). Por lo que toca a la rentabilidad de las características, la situación en cierta medida varía según la región, pese a que los factores clave que explican la caída del consumo después de la crisis fueron las fluctuaciones de la rentabilidad del tipo de empleo, la composición demográfica y el rubro "otros". Cabe señalar que durante la crisis, la proporción del deterioro del bienestar atribuible a cambios de rentabilidad fue menor en las regiones del Pacífico sur $(94,6 \%)$ y del Golfo $(103,4 \%)$, lo que indica que en estas dos últimas la crisis afectó menos al entorno económico que en el resto del país.

¿Cuál habría sido el impacto de la crisis si México

México: Descomposición de la variación del consumo por regiones (Variación porcentual)

\begin{tabular}{|c|c|c|c|c|c|c|c|c|c|c|c|c|}
\hline & \multicolumn{2}{|c|}{ Norte } & \multicolumn{2}{|c|}{$\begin{array}{l}\text { Pacífico } \\
\text { norte }\end{array}$} & \multicolumn{2}{|c|}{ Centro } & \multicolumn{2}{|c|}{ Golfo } & \multicolumn{2}{|c|}{$\begin{array}{l}\text { Pacífico } \\
\text { sur }\end{array}$} & \multicolumn{2}{|c|}{$\begin{array}{l}\text { Región urbana } \\
\text { metropolitana }\end{array}$} \\
\hline & B & $\mathrm{X}$ & $\beta$ & $\mathrm{X}$ & B & $\mathrm{X}$ & B & $\mathrm{X}$ & B & $\mathrm{X}$ & B & $\mathrm{X}$ \\
\hline \multicolumn{13}{|l|}{$1992-1994$} \\
\hline Otros & 17,31 & $0,00 *$ & $-35,07$ & $0,44 *$ & 1,02 & $0,41 *$ & 30,05 & $-0,53 *$ & $-32,68$ & $-10,04 *$ & $-51,44$ & $-0,13 *$ \\
\hline $\begin{array}{l}\text { Nivel educativo jefe de } \\
\text { hogar }\end{array}$ & 1,83 & 0,34 & $-7,89$ & 3,1 & 0,02 & 0,2 & $-2,01$ & 1,0 & 7,28 & $-3,1$ & $-16,58$ & $-2,08 *$ \\
\hline $\begin{array}{l}\text { Nivel educativo miembros } \\
\text { no jefe de hogar }\end{array}$ & 10,50 & $0,60 *$ & 13,62 & $-1,78 *$ & 17,91 & $-1,22 *$ & $-17,14$ & $-0,72 *$ & 13,74 & $1,43 *$ & 14,35 & $-0,95$ * \\
\hline Factores dem & $-29,83$ & $-0,57 *$ & $-7,43$ & $-1,10 *$ & $-31,48$ & $-1,01 *$ & $-27,16$ & $-0,94 *$ & $-11,09$ & $-1,84 *$ & $-0,43$ & $-0,40$ * \\
\hline Empleo & $-20,36$ & $-0,26 *$ & 4,87 & $-0,07 *$ & $-26,43$ & & $-26,31$ & & $-10,52$ & & $-3,35$ & 0,11 \\
\hline Vivienda & 11,67 & $0,21 *$ & 10,49 & $-0,27$ & 19,95 & 0,61 & 29,30 & 1,5 & 3,73 & -0 & 11,71 & 0,01 * \\
\hline Sector & $-5,28$ & $0,01 *$ & $-14,71$ & $0,63 *$ & $-0,85$ & $0,21 *$ & $-1,25$ & $1,95 *$ & $-10,24$ & $-2,93 *$ & 6,34 & 0,01 * \\
\hline Constante & $-86,02$ & & $-64,52$ & & $-79,61$ & & $-88,96$ & & $-43,08$ & & $-57,19$ & \\
\hline Total & $-100,18$ & 0,33 & $-100,64$ & 1,04 & $-99,47$ & $-0,51$ & $-103,48$ & 3,49 & $-82,86$ & $-17,05$ & $-96,59$ & $-3,43$ \\
\hline \multicolumn{13}{|l|}{$1994-1996$} \\
\hline Otros & $-23,81$ & $-0,84 *$ & $-24,08$ & $-0,41 *$ & $-5,67$ & $-2,12 *$ & $-22,92$ & $-2,9$ & 24,76 & 2,8 & 1,10 & $-3,82 *$ \\
\hline $\begin{array}{l}\text { Nivel educativo jefe de } \\
\text { hogar }\end{array}$ & 15,58 & $-3,93 *$ & 9,64 & $-4,1^{1}$ & $-0,83$ & $-2,92 *$ & 4,44 & $-8,1$ & $-5,79$ & $-0,57^{*}$ & 9,33 & $0,42 *$ \\
\hline $\begin{array}{l}\text { Nivel educativo miembros } \\
\text { no jefe de hogar }\end{array}$ & 9,50 & $-0,40 *$ & 14,23 & $0,29 *$ & $-8,56$ & $-1,29 *$ & 4,91 & $-0,14 *$ & $-18,37$ & $-1,41 *$ & $-0,68$ & $-0,34 *$ \\
\hline Factores demográficos & 14,45 & $0,18 *$ & 1,93 & $0,32 *$ & 13,90 & $-0,42 *$ & 34,99 & $-0,62 *$ & 13,84 & $1,90 *$ & $-4,81$ & $-0,97 *$ \\
\hline Empleo & $-1,02$ & $-0,41 *$ & $-0,11$ & & 11,58 & $0,11 *$ & 30,67 & & 17,52 & & 5,98 & $-0,18$ \\
\hline Vivienda & 2,63 & $-0,25$ & $-4,34$ & $0,05 *$ & $-5,60$ & $-0,53 *$ & $-5,79$ & $-0,36 *$ & $-12,22$ & 0,4 & $-5,57$ & $-0,13 *$ \\
\hline Sector & 10,29 & $-0,83 *$ & 15,40 & $0,37 *$ & 0,19 & $-0,42 *$ & 7,38 & $-2,02 *$ & $-2,01$ & $0,14 *$ & 0,23 & $-0,26$ \\
\hline Constante & 78,85 & & 90,76 & & 102,58 & & 59,94 & & 78,69 & & 99,69 & \\
\hline Total & 106,47 & $-6,48$ & 103,43 & $-3,43$ & 107,59 & $-7,59$ & 113,62 & $-13,62$ & 96,42 & 3,60 & 105,27 & $-5,28$ \\
\hline
\end{tabular}

Fuente: Elaborado por los autores, con datos de la Encuesta nacional de los ingresos y gastos de los hogares (ENIGH) de 1992,1994 y 1996.

* Significación conjunta a nivel del 1\%.

7 Las regiones definidas son las siguientes: Norte (Coahuila, Chihuahua, Durango, Nuevo León, San Luis Potosí, Tamaulipas, Zacatecas), Pacífico norte (Baja California Norte y Sur, Nayarit, Sinaloa, Sonora), Centro (Aguascalientes, Guanajuato, Hidalgo,
Jalisco, México, Michoacán, Morelos, Puebla, Querétaro, Tlaxcala), Golfo (Campeche, Quintana Roo, Tabasco, Veracruz, Yucatán), Pacífico sur (Colima, Guerrero, Oaxaca, Chiapas) y Metropolitana (Ciudad de México y Guadalajara). 
no hubiese hecho modificación alguna a sus características estructurales entre 1992 y 1996? Para responder a esta pregunta aplicamos las características de los hogares en 1992 a la rentabilidad de tales características en 1996, utilizando los coeficientes estimados a partir de la función de regresión correspondiente a 1996 (en consecuencia, calculamos $\hat{\beta}_{96} \bar{X}_{92}$ ). En las zonas rurales, el consumo medio previsto resultó ser $14 \%$ inferior al consumo real declarado en 1996. En las zonas urbanas, la baja correspondiente del consumo medio fue de $8 \%$. El cuadro 14 muestra estos cambios simulados, así como los que corresponden a un conjunto de indicadores de la pobreza utilizados comúnmente. En 1996, las tasas de pobreza de ambas regiones habrían sido bastante más altas de no haber variado el vector de las características $X$ de los hogares.
En las zonas rurales, el efecto de la mejora de estas características fue particularmente marcado. ${ }^{8}$

Otra manera de medir la influencia de los factores estructurales vinculados al desarrollo económico sería simular los efectos que habría tenido la crisis si se hubiera producido en 1992, lo cual equivale a comparar $\hat{\beta}_{96} \bar{X}_{92}$ con el consumo real de 1992 y no con el consumo real de 1996. Aplicando este método, el consumo medio previsto resulta inferior en $26 \%$ en las zonas rurales y en $36 \%$ en las zonas urbanas, comparado con el consumo real de $1992 .{ }^{9}$ Los resultados obtenidos mediante la aplicación de cualquiera de los dos métodos indican que los cambios estructurales que acompañan el proceso de desarrollo pueden contribuir de manera importante a mitigar los efectos adversos de la crisis económica en el bienestar de los hogares.

CUADRO 14

México: Variación porcentual simulada de los indicadores de la pobreza, usando las características de los hogares en $1992^{\mathrm{a}}$

\begin{tabular}{lcc}
\hline Indicador & Zonas rurales & Zonas urbanas \\
\hline Consumo medio & -14 & -8 \\
Incidencia de la pobreza & 48 & 25 \\
Brecha de pobreza & 45 & 33 \\
Severidad de la pobreza & 45 & 36 \\
\hline
\end{tabular}

Fuente: Elaborado por los autores, con datos de la Encuesta nacional de los ingresos y gastos de los hogares (ENIGH) de 1992,1994 y 1996.

a Las simulaciones comparan las variaciones entre $\beta_{96} \mathrm{X}_{96}$ y $\beta_{96} \mathrm{X}_{92}$.

\section{VI}

\section{La importancia}

\section{de los programas públicos}

En la presente sección evaluamos hasta qué punto los dos programas sociales más importantes de México, esto es, PROCAMPO y PROGRESA, mitigaron (o, en el caso del segundo, podrían haber mitigado) los efectos adversos de la crisis macroeconómica de 1995. En virtud de PROCAMPO se realizan transferencias en efectivo a los campesinos que en los años agrícolas comprendidos entre 1991 y 1993 hubiesen producido alguno de nueve cultivos alimentarios básicos. El programa, establecido en 1994, tiene por objetivo expreso compensar a los productores de tales cultivos por los efectos negativos que pudiera acarrear el TLC de América del Norte, y estará en vigor por 15 años. Los pagos son uniformes, se basan en una suma determinada por hectárea y no guardan relación con el uso actual de la tierra. Durante los primeros diez años del programa los pagos tendrían un valor real constante, para irse reduciendo gradualmente a lo largo de los cinco años restantes. Sin embargo, en la práctica su valor real se redujo en

\footnotetext{
8 Se realizó un análisis similar utilizando datos correspondientes a 1989 y 1996, obteniéndose resultados parecidos, los que pueden solicitarse a los autores.

9 Estos resultados también pueden solicitarse a los autores.
} 
$35 \%$ desde el inicio del programa hasta 1996. Sólo en 2001 tanto el pago por hectárea como el total de lo pagado por PROCAMPo llegó a los niveles originales de 1994. En 2002, la suma por hectárea se fijó en 875 pesos mexicanos, o 90 dólares. PROCAMPO favorece anualmente a casi tres millones de productores. De los casi 14 millones de hectáreas que abarca el programa cada año, alrededor de 79\% es de secano (Fox, 2002). El presupuesto del programa para el año fiscal 2002 ascendía a 1.240 millones de dólares, lo que representa un $60 \%$ del presupuesto de la Secretaría de Agricultura, Ganadería y Desarrollo Rural (PROCAMPO, 2002). Como los pagos del programa se hacen según la superficie en hectáreas, los predios más grandes reciben transferencias mayores. El total de las transferencias se distribuye en forma regresiva: así, un $45 \%$ de los productores cuyos predios tienen menos de cinco hectáreas recibe sólo $10 \%$ del total de las transferencias de PROCAMPO (SAGAR, 1998). Sin embargo, los pagos se distribuyen en forma progresiva según la superficie, ya que al ser uniformes por hectárea no guardan relación con los rendimientos logrados ni con el hecho de que los hogares hubiesen o no producido cultivos básicos antes de que se suscribiera el TLC.

Por su parte PROGRESA, que es el principal programa del gobierno mexicano para aliviar la pobreza, realiza transferencias en efectivo a las familias campesinas muy pobres, a condición de que cumplan con un complejo conjunto de "responsabilidades". Éstas incluyen asegurar que los hijos estén matriculados en la escuela y mantengan un $85 \%$ de asistencia, que niños y adultos se sometan periódicamente a controles médicos y programas de vacunación preventivos, y que las madres de las familias beneficiarias asistan a una charla mensual sobre temas relacionados con la salud. A cambio de esto, las familias reciben una suma en efectivo cuyo monto depende del número de hijos que asistan a la escuela y del grado de escolaridad alcanzado. Por ejemplo, en 1998 los alumnos de los grados $3^{\circ} \mathrm{a}$ $6^{\circ}$ recibían entre 7 y 12 dólares mensuales, según el grado. Los estudiantes de enseñanza media recibían entre 20 y 23 dólares mensuales, las niñas algo más que los varones. Además de estos subsidios educacionales, dos veces al año se entregaba a cada estudiante un conjunto de útiles escolares, mientras que la familia recibía un suplemento mensual de unos 10 dólares. A partir de 1997, estos pagos han aumentado $47 \%$ en valores reales. A fines de 1998, más de 1,9 millones de hogares recibían los beneficios de PROGRESA, con un gasto total de aproximadamente 900 millones de dólares. En 2001, cuando asumió el presidente Fox,
PROgResa pasó a llamarse Programa de Desarrollo Humano Oportunidades, y amplió su actividad a zonas urbanas y semiurbanas. En 2002, el presupuesto del programa se había elevado a 1.900 millones de dólares y favorecía a más de tres millones de familias campesinas y más de 1,2 millones de familias urbanas y semiurbanas (Fox, 2002).

\section{Programa de Apoyos Directos al Campo (PROCAMPO)}

La encuesta nacional de los ingresos y gastos de los hogares correspondiente a 1996 reunió información sobre el valor monetario de las prestaciones que otorgaba PROCAMPO a las familias campesinas. En la muestra rural, $16 \%$ de los hogares declararon recibir transferencias de PROCAMPO por una suma media de 402 pesos mexicanos trimestrales, en circunstancias de que el gasto real mensual per cápita del mismo grupo era de 604 pesos mexicanos. ¿Podría decirse que PROCAMPO contribuyó de manera importante a aliviar los efectos de la crisis en la población campesina?

Para responder a esta pregunta, comenzamos por estimar la relación entre las prestaciones de PROCAMPO y el consumo de los hogares, incluyendo en nuestra regresión del consumo para 1996 el valor monetario de las prestaciones. El coeficiente estimado de esta variable es 0,0002 y su valor $t$ es 7 . Utilizando estas estimaciones pronosticamos el consumo medio y tres indicadores de la pobreza (la incidencia de la pobreza, la brecha de pobreza y la severidad de la pobreza), aplicando un umbral de pobreza relativa que fijamos en el vigésimo quinto percentil del consumo en 1994. A continuación, fijamos el valor de las transferencias de PROCAMPO en 0 y simulamos los nuevos valores de estas cuatro medidas de bienestar. La variación porcentual de estos indicadores figura en la primera columna del cuadro 15 . Si no se hubiese estado aplicando el programa, el consumo medio de 1996 habría sido un 1,5\% más bajo, y todos los indicadores de la pobreza habrían sido más altos. Por ejemplo, la incidencia de la pobreza habría sido $5,1 \%$ mayor, implicando un cambio de un $28,4 \%$ (cuadro1) a un $29,8 \%$ de los hogares rurales, mientras que la severidad de la pobreza, que da mayor ponderación al bienestar de los más pobres, habría aumentado en $5,7 \%$. 
México: Efecto simulado de los programas sociales en los indicadores de la pobreza rural, 1996

(Variación porcentual)

\begin{tabular}{lcrr}
\hline Indicador & \multicolumn{2}{c}{$\begin{array}{c}\text { Si no hubiera } \\
\text { existido Procampo }\end{array}$} & \multicolumn{2}{c}{ Si hubiera existido Progresa } \\
\cline { 2 - 4 } & & $-1,5$ & Etapas 1 y 4 \\
\hline Consumo medio & 5,1 & 0,2 & 0,8 \\
Incidencia de la pobreza & 4,8 & $-1,1$ & $-6,8$ \\
Brecha de pobreza & 5,7 & $-3,2$ & $-13,2$ \\
Severidad de la brecha de pobreza & $-3,9$ & $-17,8$ & $-17,1$ \\
\end{tabular}

Fuente: Elaborado por los autores, con datos de la Encuesta nacional de los ingresos y gastos de los hogares (ENIGH) de 1992,1994 y 1996.

\section{Programa de Educación, Salud y Alimentación (PROGRESA)}

Nuestro análisis del efecto que podría tener este programa en el alivio de la pobreza resultó más complejo, debido a que PROGRESA sólo comenzó a operar a fines de 1997. En este caso, lo que nos preguntamos fue: ¿qué efectos habría tenido este programa en la pobreza si hubiera comenzado a entregar prestaciones en 1996 ?

Para responder a la pregunta debimos pasar por varias etapas. Como los datos relativos a 1996 no contienen información sobre la ayuda proporcionada por el programa, comenzamos por establecer la propensión marginal de los hogares a consumir con cargo al ingreso en efectivo, incluyendo en nuestra ecuación para 1996 el ingreso total per cápita del hogar. El coeficiente del (logaritmo del) ingreso per cápita resultó ser 0,39 y su valor $t$ igual a 46. Basándonos en este parámetro, aumentamos luego el ingreso en dinero del hogar en una suma equivalente a las prestaciones que habría recibido la familia si PROGRESA hubiese estado funcionando en 1996.

Decidimos a qué hogares asignar las prestaciones de progresa, utilizando el mismo mecanismo de focalización aplicado por el programa. Primero, designamos como pobre o no pobre a cada uno de los hogares de la muestra rural de la ENIGH, mediante el mismo método de clasificación que utiliza PROGRESA para seleccionar los hogares beneficiarios. ${ }^{10} \mathrm{~A}$ continuación, comparamos cada localidad de la muestra de la ENIGH con la base de datos de PROGRESA, para saber qué localidades serían eventualmente incorporadas al programa y en qué etapa fueron incorporadas. Aplicando este método pudimos determinar cuáles fueron los hogares de la muestra de la ENIGH de 1996 que se transformaron posteriormente en beneficiarios de

10 Para una descripción de este proceso, véase Skoufias, Davis y de la Vega (2001).
PROGRESA, y cuándo lo hicieron. De este modo pudimos comprobar que un $55 \%$ de los hogares rurales de la ENIGH de 1996 fueron incorporados posteriormente a PROGRESA. De esos beneficiarios futuros, un $15 \%$ se incorporó en las dos primeras etapas del programa y el $70 \%$ en la cuarta etapa.

Calculamos la suma que recibiría cada uno de estos futuros hogares beneficiarios según la edad, sexo, matrícula escolar y escolaridad de los hijos. La evaluación incluyó también el valor monetario de los útiles escolares proporcionados. Utilizando el monto de estas posibles transferencias y la propensión marginal a consumir con cargo al ingreso monetario, simulamos variaciones porcentuales de los indicadores de bienestar a partir de distintos supuestos sobre la cobertura de PROGRESA en 1996. Los resultados figuran en las tres últimas columnas del cuadro 15 .

El primer supuesto simulado fue que a fines de 1996 sólo se habían completado las dos primeras etapas de Progresa. Probablemente éste sea el supuesto más realista, dado el momento en que se produjo el shock macroeconómico y lo difícil que resultó poner en marcha el programa. En este marco hipotético, la incidencia de la pobreza habría disminuido $1,1 \%$ y la severidad de la pobreza habría bajado 3,9\%. Si a fines de 1996 hubiese estado completada la cuarta etapa de PROGRESA, la incidencia de la pobreza habría sido $6,8 \%$ más baja, la brecha de pobreza habría disminuido $13 \%$ y la severidad de la pobreza se habría reducido en $17,5 \%$. De haberse completado totalmente el programa, la baja de los indicadores de la pobreza habría sido aún mayor $(8,8 \%$ en la incidencia de la pobreza, $17 \%$ en la brecha de pobreza y $22,5 \%$ en la severidad de la pobreza). ${ }^{11}$ Este último escenario implica un aumento de la

11 De hecho, en 1996 el nivel real previsto de la brecha de pobreza y de la severidad de la pobreza es bajo, puesto que el método de mínimos cuadrados ordinarios (MCO) sobrestima los valores más pequeños de la variable dependiente y subestima los más grandes. 
incidencia de la pobreza en los hogares rurales, de $28,4 \%$ a $30,9 \%$. Si bien esta última hipótesis resulta poco realista para 1996, permite yuxtaponer las cifras del presupuesto total de PROCAMPO/ PROGRESA y de esta manera comparar peso por peso sus efectos en la pobreza. Además, nos permite formarnos una idea sobre la medida en que el actual programa Oportunidades podría servir de red de protección si se produjera una crisis macroeconómica como la de 1995. Obsérvese además que PROGRESA influye más que PROCAMPO en la mitigación de la brecha de pobreza y la severidad de la pobreza, porque el primero está dirigido a las familias campesinas más pobres.

\section{VII}

\section{Conclusiones e inferencias de política}

En este trabajo investigamos las relaciones recíprocas de la política, las reformas estructurales y el comportamiento de los hogares en el período de grave crisis económica que se vivió en México en 1995. Los resultados ponen de relieve a la vez la importancia de las metas de desarrollo a mediano plazo y de las medidas de protección social a corto plazo que se adopten para aliviar los efectos adversos de un shock macroeconómico. Encontramos, primero, que los hogares pobres reaccionan en forma significativa y prevista a una caída del ingreso. Los hogares aumentan la proporción del presupuesto destinada al consumo de alimentos y dentro de ésta, al de cereales y frutas y legumbres. Las diferencias en la composición de la canasta de alimentos entre los hogares rurales y urbanos tienen consecuencias para la política de precios de los alimentos. En el campo, predominan en la canasta los cereales y las hortalizas, frutas y legumbres, mientras que en las zonas urbanas predominan las carnes y el pescado y los alimentos consumidos fuera del hogar. Sin embargo, las modalidades de consumo de alimentos de los más pobres de las zonas urbanas (quintil inferior) se asemejan a aquellas de los hogares campesinos, pero no así a las de los hogares campesinos pobres.

En segundo lugar, comprobamos que la crisis económica generó una baja de las tasas de matrícula escolar, en especial de las niñas pobres de las zonas urbanas. Estas variaciones son inquietantes, por cuanto representan posibles costos a largo plazo de la crisis. Tanto en los hogares urbanos como en los rurales, la caída de las tasas de matrícula guardó relación con el ingreso del hogar. Mientras más alto fuera el ingreso del hogar, mayores eran las probabilidades de que los niños estuvieran matriculados en la escuela.

Tercero, antes de que se produjera la crisis del peso, México había tenido cinco años de crecimiento, acompañados de reestructuración económica, mejora de los indicadores sociales y reducción de la pobreza. El análisis ofrecido en este trabajo indica que los cambios en las características de la economía y de los hogares registrados entre 1992 y 1996 contribuyeron a mitigar los efectos de la crisis. Las simulaciones revelan que de no haberse producido esos cambios, durante la crisis la pobreza habría sido mucho más acentuada. Los resultados obtenidos entrañan que las estrategias económicas que centran la atención exclusivamente en el crecimiento y no aseguran el desarrollo a mediano plazo (mediante el acceso a la educación, por ejemplo) pueden tener costos muy altos, especialmente en épocas de crisis macroeconómica.

Finalmente, los resultados del estudio también nos dejan algunas enseñanzas sobre el diseño e impacto de los programas. Pese a que fue concebido para estimular la inversión en el desarrollo a largo plazo del capital humano de los más pobres, el programa PROGRESA aplicado en México podría cumplir una función importante de protección social en una crisis macroeconómica. Las simulaciones realizadas muestran que si el programa hubiera estado operando en 1996, la brecha de pobreza y la severidad de la pobreza habrían sido muy inferiores a las registradas ese año. Este resultado tiene importancia para otros países de América Latina -como Nicaragua, Honduras y Brasil-que estén contemplando o aplicando medidas por el lado de la demanda para aumentar el capital humano de los más pobres. Sin embargo, la clave del éxito dependerá de que se apliquen mecanismos de focalización adecuados para asegurar que los programas favorezcan a los más pobres. 


\section{Bibliografia}

Banco de México (1999): http://www.banxico.org.mx, noviembre.

CEPAL (Comisión Económica para América Latina y el Caribe) (2002): Panorama social de América Latina, 2001-2002, LC/G.2183-P, Santiago de Chile, octubre. Publicación de las Naciones Unidas, $\mathrm{N}^{\circ}$ de venta: S.02.II.G.65.

CONAPO (Consejo Nacional de Población) (1997): La situación demográfica de México, México, D.F.

Deaton, A. y J. Muellbauer (1980): Economics and Consumer Behavior, Cambridge, Cambridge University Press.

Fox, V. (2002): Informe de gobierno, 2002, México, D.F., septiembre, http:/informe.presidencia.gob.mx/Informes/2002Fox2/website/ $\mathrm{cfm} /$ index.cfm.

Hernández-Laos, E. (1990): Medición de la intensidad de la pobreza y de la pobreza extrema en México, Investigación económica, vol. 49, No 191, México, D.F., Universidad Nacional Autónoma de México (UNAM)

INEGI (Instituto Nacional de Estadística Geografía e Informática) (1999):http://www.inegi.gob.mx/inegi/default.asp , noviembre.

Lustig, N. y M. Székely (1998): México: evolución económica, pobreza, y desigualdad, en E. Ganuza, L. Taylor y S. Morley (comps.), Politica macroeconómica y pobreza en América Latina y el Caribe, Madrid, Mundi-Prensa.
Oaxaca, R. (1973): Male-female wage differentials in urban labor markets, International Economic Review, vol. 14, Filadelfia, University of Pennsylvania.

(1998): On discrimination and the decomposition of wage differentials, Journal of Econometrics, vol. 61, № 3 , Amsterdam, Elsevier Science.

PROCAMPO (Programa de Apoyos Directos al Campo) (2002): Resultados principales del 3er trimestre del año físcal 2002, octubre, www.procampo.gob.mx.

Programa Nacional de Acción a favor de la Infancia, 1995-2000 (1998): Evaluación 1998, México, D.F., Comisión Nacional de Acción a favor de la Infancia.

SAGAR (Secretaría de Agricultura, Ganadería y Desarrollo Rural) (1998): PROCAMPO, 1994-1998, Claridades agropecuarias, $\mathrm{N}^{\circ} 64$, México, D.F., diciembre.

Skoufias, E., B. Davis y S. de la Vega (2001): Targeting the poor in Mexico: an evaluation of the selection of households into PROGRESA, World Development, vol. 29, Nº 10, Amsterdam, Elsevier Science.

Székely, M. (1998): The Economics of Poverty, Inequality, and Wealth Accumulation in Mexico, Londres, Macmillan/St. Antony's College. 